\title{
Tabularia
}

\section{L'écrit et la justice au Mont Saint-Michel : les notices narratives (vers 1060-1150)}

Justice and writing practices in the Mont St-Michel: The narrative notices

(towards 1060-1150)

\section{Éric Van Torhoudt}

\section{(2) OpenEdition \\ Journals}

Édition électronique

URL : http://journals.openedition.org/tabularia/813

DOI : $10.4000 /$ tabularia. 813

ISSN : 1630-7364

Éditeur :

CRAHAM - Centre Michel de Boüard, Presses universitaires de Caen

Référence électronique

Éric Van Torhoudt, « L'écrit et la justice au Mont Saint-Michel : les notices narratives (vers

1060-1150) », Tabularia [En ligne], La résolution des conflits et l'écrit, mis en ligne le 24 octobre 2007, consulté le 30 avril 2019. URL : http://journals.openedition.org/tabularia/813 ; DOI : 10.4000/ tabularia.813 


\title{
L'écrit et la justice au Mont Saint-Michel: les notices narratives (vers 1060-1150)
}

\section{Justice and writing practices in the Mont St-Michel: The narrative notices (towards 1060-1150)}

\author{
Éric VAN TORHOUDT \\ CRAHM-UMR 6577 \\ Université de Caen Basse-Normandie \\ evantorhoudt@wanadoo.fr
}

Résumé:

Les pratiques montoises en matière d'écrits judiciaires sont comparables à celles des monastères ligériens. La série des notices narratives conservée dans le cartulaire commence avec l'abbatiat de Renouf (1055-1084/1085), connaît son apogée avec l'abbé Bernard (1131-1149) et s'éteint avec la mise en chantier du cartulaire vers 1149/1150. La forme de ces écrits poursuit la tradition diplomatique et historiographique du scriptorium montois et trouva naturellement sa place dans le cartulaire chronique. Les moines y mettent en scène leur autonomie à l'égard des ducs ou des évêques et y soulignent les qualités de certains de leurs abbés. Les sept exemples étudiés ici sont des comptes rendus d'accords qui se désignent eux-mêmes comme des pacta ou des conventiones. Ces textes, assemblant formules diplomatiques, extraits de chartes antérieures et passages narratifs, sont des patchworks alternant les styles subjectifs et objectifs afin de reconstituer un scénario immuable débouchant sur le repentir des laïcs. La procédure exceptionnelle du judicium n'est qu'un élément d'une négociation qui fait intervenir un large panel d'amis, de parents ou de personnages d'autorité, laïques ou ecclésiastiques, qui ne s'interposent pas pour «dire le droit» ou exécuter une sentence, mais pour valider une preuve écrite ou défendre leurs propres intérêts. L'objectif n'est pas l'application d'une norme juridique, mais l'apaisement des faides et le rétablissement de la concorde par le compromis et la rénovation du lien social. La compréhension de ces textes nécessitent une lecture «entre les lignes» attentive à l'implicite.

Mots-clés: diplomatique, Normandie, pouvoirs locaux, conflits, dîme, Mont-Saint-Michel, autorité ducale, féodalité, faides.

\section{Abstract:}

The practices in the Mont as regards judiciary writings are comparable to the ones of the ligerian monasteries. The series of narrative notices kept in the cartulary begins under the rule of abbot Renouf (1055-1084/1085), thrives with abbot Bernard (1131-1149) and ends with the beginning of the writing of the cartulary towards 1149/1150. The form of these writings follows the diplomatic and historiographic tradition of the scriptorium of the Mont St Michel and finds a natural place in the chronic cartulary. The monks stage in them their autonomy from the earls or the bishops and underline the qualities of some of their abbots. The seven examples studied here are records of agreements which qualify themselves as pacta or conventiones. 
These texts putting together diplomatic formulas, excepts from previous charts and narrative episodes, are patchworks which display alternatively subjective and objective styles so as to recreate an unchanging scenario leading to the repentance of the laymen. The exceptional procedure of the judicium is only one element of a negotiation in which a large array of friends, parents, people endowed with authority, laymen or ecclesiastics, intervene, not to "say the law" or execute a sentence, but to validate a written proof or protect their own interests. The purpose is not the application of a judicial norm, but the appeasement of feuds and the restoration of concord through compromise and the renewing of the social links. To understand these texts requires the ability to read "between the lines" and to pay much heed to the implicit part of them.

Keywords: diplomatic, Normandy, local power, disputes, tithe, Mont Saint-Michel, ducal authority, feudal system, feuds.

Quelle fut la place de l'écrit dans la résolution des conflits, à l'ombre de l'archange? Les archives du Mont Saint-Michel conservent une série de notices narratives traitant $\mathrm{du}$ règlement de conflits. Chacune retrace, dans un véritable récit, l'historique d'une acquisition ou d'une contestation sur deux, voire trois générations ${ }^{1}$. Cette pratique rappelle les chartriers ligériens de SaintMartin de Marmoutier ${ }^{2}$, de la Trinité de Vendôme ${ }^{3}$ ou de Saint-Aubin d'Angers ${ }^{4}$. En revanche, elle n'est pas généralisée dans les scriptoria de la principauté normande, dont les actes longs et récapitulatifs (c'est-à-dire relatant plusieurs actions distinctes) prirent le plus souvent la forme de pancartes ${ }^{5}$ ou de chartes

1. J'emprunte l'expression de «notices narratives» à Dominique Barthélemy par opposition aux "actes conventionnels" (BarthéLÉmy, Dominique, La société dans le comté de Vendôme de l'an mil au XIV siècle, Paris, Fayard, 1993, p. 30-32, p. 61-69, p. 91-98, p. 111-113 et Annexe II). L'auteur a mis en évidence l'émergence du «nouveau style » des notices circonstanciées «à rallonge » à partir de 1060, ainsi qu'un «âge classique» de la notice narrative entre 1090 et 1130. Michel Parisse utilise aussi l'expression de «notices-pancartes» pour les désigner (PARIsSe, Michel, «Écriture et réécriture des chartes: les pancartes aux $\mathrm{XI}^{e}$ et $\mathrm{XII}$ e siècles», in Pratiques de l'écrit documentaire au XI ${ }^{e}$ siècle, Olivier Guyotjeannin, Laurent Morelle, Michel Parisse (éd.), Paris, Bibliothèque de l'École des chartes, t. 155, janvier-juin 1997, p. 249-250). On pourrait enfin qualifier de «notices-chartes» celles construites essentiellement au style subjectif (cf. infra).

2. D'ailleurs les prieurés dépendant de cette abbaye et de ses voisines ligériennes en fournissent des exemples pour l'Avranchin: contestation vers 1060 de la fondation du prieuré de Saint-Cyr-deBailleul (Manche, cant. Barenton) par le moine Hugue frère de Garin (Émile-Auber Pigeon, Le diocèse d'Avranches, Coutances, Salettes, 1888, $\mathrm{n}^{\circ}$ III, p. 672- 673).

3. Voir n. 1, supra.

4. BarthéLÉMY, Dominique, «Une crise de l'écrit? Observation sur les actes de Saint-Aubin d'Angers (XI' siècle)», in Pratiques de l'écrit documentaire..., p. 95-118.

5. Le terme de pancarte doit être réservé aux documents récapitulatifs reproduisant la forme originale d'actes (ce qui pose la question de l'état initial de l'enregistrement des transactions) rassemblés afin de recevoir collectivement l'authentification d'une autorité laïque ou ecclésiastique. Ce type est désormais bien étudié par David Bates (BATEs, David «Les chartes de confirmation et les pancartes normandes du règne de Guillaume le Conquérant», in Pancartes monastiques des XI ${ }^{e}$-XII ${ }^{e}$ siècles, Turnhout, Brepols, 1998, p. 95-109; PARISSE, «Écriture et réécriture des chartes... », p. 250-252), après Lucien Musset (Musset, Lucien, Les actes de Guillaume le Conquérant et de la reine Mathilde pour les abbayes caennaises, Caen [Mémoire de la Société des Antiquaires de Normandie], t. XXXVII, 1967, p. 25-41). 
confirmatives ducales ${ }^{6}$. Le dénominateur commun de toutes ces pratiques est une conception dynamique de l'archivage par des réécritures continuelles s'adaptant à l'évolution des réalités sociales, politiques ou économiques ${ }^{7}$.

Dans ce panorama touffu, les archives de l'abbaye du Mont Saint-Michel se distinguent par leur prédilection pour les notices narratives ${ }^{8}$. Le cartulaire du Mont Saint-Michel est composé de trois parties distinctes:

- Une Historia ( $\mathrm{f}^{\circ}$ 5-19) composée de deux récits: l'un raconte la fondation de l'abbaye sur le Mont Tombe, intitulé Revelatio ecclesiae sancti Michaelis ${ }^{9}$; l'autre, connu sous le titre d'Introductio monachorum, rapporte l'introduction de la réforme bénédictine au $\mathrm{X}^{\mathrm{e}}$ siècle;

- Un cartulaire original ( $\left.\mathrm{f}^{\circ} 2 \mathrm{O}-112\right)$ constitué de 118 chartes et compilé sous l'abbatiat de l'évêque Geoffroi (mai 1149-décembre 1150/janvier 1151). Il vient d'être édité par Katharine Keats-Rohan, qui avait publié une série d'articles préalables ${ }^{10}$;

- Un registre $\left(\mathrm{f}^{\circ} 112 \mathrm{v}^{\circ}-126\right)$ des actes établis durant l'abbatiat de Robert de Torigni (27 mai 1154-24 juin 1186). La fin du volume de la bibliothèque d'Avranches est constituée de chartes du XIII ${ }^{\mathrm{e}}$ siècle.

Le Mont fut l'un des rares établissements monastiques normands dont le scriptorium ne produisit ni pancarte ${ }^{11}$ ni charte de confirmation générale, après

6. Même si l'exclusivité ducale sur l'authentification des actes s'effrita progressivement après le règne de Richard II (PotTs, Cassandra, "The early Norman charters: a new perspective on an old debate», in England in the eleventh century, Stanford, 1992, p. 31-36), les diplômes de confirmation générale illustrent le rôle primordial des ducs dans l'authentification des transactions jusqu'à la fin du règne de Guillaume le Conquérant (BATES, David, «La mutation documentaire et le royaume anglo-normand (seconde moitié du XIe siècle-début du XII ${ }^{e}$ siècle) ", in Les actes comme expression du pouvoir au Moyen Âge, Turnhout, Brepols, 2003, p. 42).

7. La manière dont les listes de signa furent complétées durant plusieurs décennies, parfois sur des exemplaires distincts des mêmes documents, illustre cette manière de concevoir l'acte écrit comme un instrument vivant, dont la forme et le contenu étaient réactualisés et s'adaptaient au moment de son utilisation. Sur les listes de signa, voir Pоттs, "The early Norman charters...», p. 34; BAtes, David, Regesta Regum Anglo-Normannorum. The acta of William I (1066-1087), Oxford, Clarendon Press, 1998 (désormais Acta of William I), p. 22-30 et pour l'exemple de l'abbaye de Lessay, $\mathrm{n}^{\circ} 175$, p. 577-584.

8. Cartulaire du Mont Saint-Michel (Livre vert du XII ${ }^{\mathrm{e}}$-XIII ${ }^{\mathrm{e}}$ siècle), Bibl. mun. Avranches, ms. 210.

9. LelÉGARD, Marcel, «Saint Aubert», in Millénaire monastique du Mont Saint-Michel, t. I, Histoire et vie monastique, Bibliothèque d'histoire et d'archéologie chrétienne, Paris, P. le Thielleux, 1967, p. 40-41; Bouet, Pierre, «La Revelatio et les origines du culte à saint Michel sur le Mont Tombe", in Cultes et pèlerinages à saint Michel en occident. Les trois monts dédiés à l'archange, Pierre Bouet, Giorgio Otranto, André Vauchez (dir.), Rome [Collection de l'École française de Rome, 316], 2003, p. 64-90.

10. The cartulary of the abbey of Mont Saint-Michel, éd. Katharine S. B. Keats-Rohan, Donington [Shaun Tyas], 2006 (les actes étudiés dans le présent article sont référencés dans ce volume indiqué désormais Cartulary of Mont Saint-Michel); EAD., "Bibliothèque municipale d'Avranches, 210: Cartulary of Mont-Saint-Michel », Anglo-Norman Studies, t. XXI, 1999, p. 95-112; EAD., «Une charte de l'abbé Mayeul de Cluny et la réforme du Mont Saint-Michel», in La Normandie vers l'an mil, Rouen [Société d'Histoire de Normandie], 200o, p. 159-169; EAD., «L'histoire secrète d'un sanctuaire célèbre. La réforme du Mont Saint-Michel d'après l'analyse de son cartulaire et de ses nécrologes ", in Cultes et pèlerinages à saint Michel..., p. 139-159)

11. Avec Fécamp et Saint-Ouen de Rouen, cette exception touche trois abbayes normandes parmi les plus anciennes, disposant de fonds d'archives importants et de confirmations de Richard II; 
$1026^{12}$. Ce style documentaire était particulièrement adapté aux «chroniques judiciaires ${ }^{13}$. D'ailleurs, dans son édition des actes de Guillaume le Conquérant, David Bates a classé ce mode d'archivage parmi les comptes rendus de plaids et les conventiones ${ }^{14}$.

Cette étude envisage la relation entre l'écrit et la justice sous deux aspects: comment les notices narratives rendaient-elles compte de la résolution des conflits d'une part et d'autre part, quels furent la place et l'usage de l'écrit dans le processus judiciaire?

\section{La résolution des conflits dans l'écrit}

Les actes longs représentent $29 \%$ des actes du cartulaire du Mont SaintMichel. On dénombre 13 notices longues pour 45 actes entre 1066 et 1144, dates d'apparition et de disparition de ce genre. Le nombre d'actes conservés varie selon les abbatiats. Deux abbés se distinguent nettement au XI ${ }^{e}$ siècle et durant la première moitié du XII e siècle, Renouf (1055-1084/1085) et Bernard (1131-1149). Les abbés pour lesquels peu d'actes ont été conservés sont ceux réputés avoir eu des difficultés avec la communauté des moines ${ }^{15}$.

Répartition des actes normands du Mont Saint-Michel:

\begin{tabular}{|c|c|c|c|}
\hline Abbés & Abbatiats & Nombre d'actes & Moyennes annuelles \\
\hline Huit premiers abbés & $1009-1053 / 1055$ & 15 & 0.32 \\
\hline Renouf & $1053 / 1055-1084 / 1085$ & 19 & 0.79 \\
\hline Roger I ${ }^{\text {er }}$ & $1085-1106$ & 4 & 0.19 \\
\hline Roger II & $1106-1123 / 1124$ & 3 & 0.18 \\
\hline Richard & $1124-1128$ & 3 & 0.43 \\
\hline Bernard & $1131-1149$ & $18^{16}$ & 1 \\
\hline Geoffroi et Richard & $1149-1153$ & $o$ & $o$ \\
\hline
\end{tabular}

elles rédigèrent des notices narratives avant 1080 (Acta of William I, p. 30 et pour Fécamp, $\mathrm{n}^{\circ}{ }^{142-}$ 143-145-146) et elles furent aussi les premières à élaborer des cartulaires entre la fin du XI siècle et le milieu du XII e siècle (BATES, "Les chartes de confirmation et les pancartes normandes...", p. 100 ; Acta of William I, p. 25).

12. La seule confirmation générale fut celle de Richard II vers 1022/1026 (FaUroux, Marie, Recueil des actes des ducs de Normandie (911-1066), Caen [Mémoire de la Société des Antiquaires de Normandie, t. XXXVI], 1967 (désormais $R A D N$ ), $\mathrm{n}^{\circ}$ 49, p. 158-162); son fils Robert le Magnifique (1027-1035) se contenta, dans une charte brève, d'étendre sa protection globale à l'ensemble des possessions de l'abbaye $\left(R A D N, \mathrm{n}^{\circ} 65, \mathrm{p} .195-197\right.$ et $\left.R A D N, \mathrm{n}^{\circ} 73, \mathrm{p} .212\right)$; à partir de Guillaume le Bâtard, les ducs authentifièrent des chartes privées (RADN, $\mathrm{n}^{\circ}$ 110-132-133) ou des conventiones (RADN, $\mathrm{n}^{\circ}$ 148-232; Acta of William $\left.I, \mathrm{n}^{\circ} 214\right)$.

13. Benoît-Michel Tock date l'apparition de la notice (rédigée à la troisième personne) à Jumièges de 1069/1070 (Tоск, Benoit-Michel, «Les chartes originales de l'abbaye de Jumièges jusqu'en 1120 », Tabularia «Études», n 2, 2002, p. 5; voir aussi BATES, «La mutation documentaire...», p. 39-40 et p. 44).

14. Acta of William I, p. 30-35.

15. DufIef, André, «La vie monastique au Mont Saint-Michel pendant le XII siècle», in Millénaire monastique du Mont Saint-Michel, t. I, Histoire et vie monastique, Paris, 1966, p. 82-101.

16. Katharine Keats-Rohan a dénombré 29 actes pour l'abbatiat de Bernard soit une moyenne annuelle de 1,6 (Keats-Rohan, «Une charte de l'abbé Mayeul de Cluny...», p. 160). Mais 11 de ces actes sont destinés à d’autres régions que la Normandie. 
Renouf, abbé de 1053/1055 à 1084/1085, fut l'initiateur de cette nouvelle forme diplomatique (deux notices longues). Sous l'abbatiat de Bernard (1131-1149), les notices demeurèrent très circonstanciées, donnant l'image d'un abbé très actif et énergique dans la défense des intérêts de son monastère. Entre ces périodes de production soutenue d'écrits, s'intercalent quarante-six années, avec une dizaine d'actes en tout, d'où n'émergent que la notice-charte de Saint-Jean le Thomas. L'abbatiat éclair de Geoffroi (1149-1150) qui mit en chantier le cartulaire ${ }^{17}$ vint clore la phase des notices, marquant nettement la fin d'un style ${ }^{18}$. Ce style documentaire est-il la manifestation d'une évolution des pratiques judiciaires et peut-on parler d'une «mutation documentaire» au Mont Saint-Michel vers $1060 / 1080^{19}$ ?

Les grandes notices du Mont Saint-Michel, dont le contenu a fait l'objet d'une réécriture complète et profonde, sont de véritables patchworks. Sept ont retenu mon attention en raison de leur intérêt concernant la résolution de conflits. Il ne s'agit pas à proprement parler de notices de plaids ou de procès verbaux de jugements ${ }^{20}$ qui, comme nous le verrons, étaient des procédures rares. Ce sont plutôt des comptes rendus d'accords qui se désignent eux-mêmes comme des pacta ou des conventiones:

1. Carta de Poterel ${ }^{21}$ - Au temps de l'abbé Renouf (1053/1055-1084/1085 ${ }^{22}$ ), Gerbert de Poterel ${ }^{23}$ donna la moitié de sa terra qu'il tenait en service libre de l'abbaye. Ensuite l'abbé acheta l'autre moitié à un certain Roger pour dix livres mancelles et une terra à Hérenguerville ${ }^{24}$. Mais, longtemps après que l'abbé eut transformé la terre de Poterel en métairie (medietariam), Roger assassina le porcher de l'abbaye dans le bois de Bevais ${ }^{25}$. L'abbé porta clameur au comte de Normandie qui exila l'assassin. Roger ne put rentrer qu'après avoir conclu un pactum avec l'abbé, scellé par une conventio, en présence du duc qui corrobora l'acte en 1066;

2. Carta de molendino comitis ${ }^{26}$ - La contestation (calumnia) de Jean fils de Richard, concernant le moulin du comte à Vains ${ }^{27}$, fut promptement étouffée

17. Keats-Rohan, «Bibliothèque municipale d'Avranches, 210... », p. 95-112; EAD., "Une charte de l'abbé Mayeul de Cluny... », p. 159-16o.

18. Dernier exemple relatant deux affaires: 1142/1144, Pierre de Saint-Hilaire [-du-Harcouët] (Manche, ch.-l. cant.) viole un accord passé avant la mort d'Henri I ${ }^{\text {er }}$ puis se soumet (Cartulary of Mont Saint-Michel, $\mathrm{n}^{\circ}$ 116).

19. BATES, «La mutation documentaire...», p. 33-49.

20. RADN, p. 36-37.

21. Cartulary of Mont Saint-Michel, $\mathrm{n}^{\circ} 70$, Carta de Poterel; RADN, $\mathrm{n}^{\circ}$ 232, p. 446-448.

22. Les dates des abbatiats sont données d'après les travaux prosopographiques de Véronique Gazeau (Gazeau, Véronique, Recherches sur l'histoire de la principauté normande (911-1204), t. II, Prosopographie des abbés bénédictins (911-1204), Mémoire d'habilitation, Paris, 2002 (dactyl.), p. 162-176.

23. Poterel, Manche, cant. Sartilly, comm. Dragey.

24. Hérenguerville, Manche, cant. Montmartin-sur-Mer.

25. Manche, cant. Sartilly, comm. Saint-Michel-des-Loups, Carolles, Champeaux et Angey (forêt disparue).

26. Cartulary of Mont Saint-Michel, $\mathrm{n}^{\circ} 6$; RADN, $\mathrm{n}^{\circ}$ 148, p. 330-333; Acta of William I, $\mathrm{n}^{\circ} 214, \mathrm{p} .672-$ 675 .

27. Vains, Manche, cant. Avranches. 
par un jugement royal. Ce moulin avait été donné à l'abbaye par le duc Robert le Magnifique (1026/1027-1035), puis l'abbé Suppo (1033-1042/1048) l'avait cédé à Renouf le monétaire contre la volonté des moines. Ensuite Guillaume le Bâtard (1061) en avait confirmé le rachat par l'abbé Renouf à Waleran fils du monétaire et à ses parents ${ }^{28}$. Quinze ans plus tard (vers 1076), le roi ordonna la réunion de la cour royale, présidée par l'évêque de Coutances Geoffroi, afin de condamner Jean fils de Richard. Le jugement reçut la souscription ducale;

3. Carta Thome de Sancto Johanne ${ }^{29}$ - Pour l'édification d'un château, Thomas de Saint-Jean dévasta des bois ainsi que les terrae de plusieurs vavasseurs dans les honneurs de Saint-Pair et de Genêts ${ }^{30}$. Les moines instituèrent une très pieuse clamor liturgique, chantant sans interruption le Miserere et le Kyrie eleison, afin que le malfaiteur soit châtié. Furieux et inquiet, Thomas vint au Mont avec ses frères Jean et Roger, pour s'informer des raisons de cette plainte. Il reconnut sa faute et il se prosterna aux pieds de l'abbé Roger II (1106-1123), implorant son pardon. Après plusieurs jours de négociations, dont la teneur est rapportée par les discours successifs des protagonistes, un compromis fut trouvé, partageant les droits et les revenus entre les moines et le seigneur de Saint-Jean qui, après son frère Roger, fit son hommage à l'abbé. Thomas et sa famille furent admis au bénéfice spirituel de l'abbaye. Le texte de l'accord fut établi au temps de l'abbé Roger, puis son successeur Richard de Mere (1123/1124-1128) le fit confirmer par le roi Henri ${ }^{\text {er }}$ et enfin Thomas et ses frères réitérèrent leur confirmation à l'abbaye;

28. Cette notice présente l'intérêt d'appartenir à un dossier publié par Marie Fauroux: $R A D N, \mathrm{n}^{\circ} 148$ A1, p. 331, charte par laquelle le comte de Normandie reconnaît avoir reçu de l'abbé Renouf 30 livres pour le moulin de Vains; RADN, $\mathrm{n}^{\circ} 148$ A2, p. 331-332, reconnaissance par la cour ducale de la propriété des moines sur le moulin, datée de 1061; RADN, $\mathrm{n}^{\circ} 148 \mathrm{~A} 3$, p. 332-333, extrait de la notice, adaptée de A2, enregistrant le jugement prononcé contre Jean fils de Richard, dans laquelle fut copiée A1; sur Renouf le monétaire et son fils Waleran, voir Musset, Lucien, «At-il existé en Normandie au $\mathrm{XI}^{\mathrm{e}}$ siècle une aristocratie d'argent?", Annales de Normandie, t. 9, $\mathrm{n}^{\circ} 4$, décembre 1959, p. 285-299.

29. Cartulary of Mont Saint-Michel, $\mathrm{n}^{\circ} 16$; BnF, ms. nouv. acq. lat. 1428, $\mathrm{f}^{\circ} 175-178$ (sur l'historique de ce fonds, voir BATEs, David, «Four recently rediscovered norman charters", Annales de Normandie, t. 45, $\mathrm{n}^{\circ}$ 1, mars 1995, p. 35-36, n. 5); British Library, additional charters, $\mathrm{n}^{\circ} 66$ 980, copie lacunaire interrompue au milieu d'un mot fo pour forisfeci, $\mathrm{f}^{\circ} 38$, dont les omissions ne paraissent pas intentionnelles et susceptibles de modifier le sens du texte; Johnson, Charles, Cronne Henry Alfred, Regesta regum Anglo-Normannorum, 1066-1154, t. II, Regesta Henrici Primi, Oxford, 1956, Calendar ${ }^{\circ}$ 1422, éd. ${ }^{\circ}$ Clxxiv (Cirographum Thome de Sancto Johanne), p. 351-352; BousSARD, Jacques (éd.), "Thomas de Saint-Jean le Thomas et l'abbaye du Mont Saint-Michel», in Droit privé et institutions régionales. Études historiques offertes à Jean Yver, Rouen, Publications de l'université de Rouen, 1976, p. 87-96. Jacques Boussard avait noté l'intérêt de ce document pour l'étude du régime féodal en Normandie au début du XII ${ }^{\mathrm{e}}$ siècle. Mais, le texte appelle aussi d'autres remarques concernant l'usage et la place des actes écrits dans la justice au Mont SaintMichel.

30. Saint-Jean-le-Thomas, Manche, cant. Sartilly; il s'agit des bois de Neirum (Manche, cant. Sartilly, comm. Champeaux), Crapault (Manche, cant. Sartilly, comm. Carolles) et Bevais (Manche, cant. Sartilly, comm. Saint-Michel-de-Loups et Angey); Saint-Pair, Manche, cant. Granville; Genêts, Manche, cant. Sartilly. 
4. De Carterio ${ }^{31}-$ Cette notice relate deux affaires:

4a - En 1125, Richard de Carteret donna l'église de Saint-Germain ${ }^{32}$. Dix ans plus tard (1135), ses fils Philippe, Geoffroi et Onfroi ainsi que sa veuve Lucie, dénoncèrent cette aumône mais, convoqués devant l'abbé Bernard (1131-1149) et le chapitre abbatial, ils reconnurent ce don en échange de compensations;

$4 \mathrm{~b}$ - Quelques temps après, le prêtre Roger se faisant moine, ses héritiers renoncèrent aux revenus de l'autel et reçurent de l'abbé des compensations financières. Pourtant, après la mort du roi Henri (1135), les habitants de la villa conspirèrent contre les moines. Lors de deux confrontations successives, l'abbé obtint des serments de fidélité qui ne furent pas respectés. Enfin, l'abbé réunit un plaid (curia) qui démasqua les malfaiteurs. Les libres de la villa et les puissants de la province condamnèrent au bannissement les héritiers de Roger (avant 1149).

5. De ecclesia de Husnis ${ }^{33}$ - Jean fils de Garnier, souhaitant prendre l'habit monastique donna, avec le consentement de l'évêque d'Avranches Turgis (1096-1133), l'église d'Huisnes ${ }^{34}$ et la moitié de la terra de son patrimoine qu'il partageait avec son frère Ilgerius. Après quinze ans, durant lesquels les moines tinrent cette aumône en paix, deux neveux de Jean réclamèrent l'église et la terra. Alors l'abbé Bernard réduisit à néant leurs prétentions. Ils vinrent à pied à l'abbaye et demandèrent que ces biens leur soient affermés. Conseillé par l'évêque d'Alet Donoald (1119/1120-1142) et l'abbé de Saint-Sever Robert, Bernard accepta contre 22 sous manceaux de fermage annuel (1131/1142);

6. De homine huic ecclesie redditio in Guernereio ${ }^{35}$ - Richard fils de Robert Malmarche, conseillé par son oncle Robert de Grentais, restitua aux moines la terra du Grand Moulin à Guernesey pour laquelle il avait été excommunié, comme son père qui, à la veille de sa mort, s'était hâté de faire cette restitution. Dénudé devant l'autel de saint Michel où il avait publiquement déposé sa restitution, Richard fut battu avec des verges par le prieur et les moines. En présence de nombreux témoins tant clercs que laïcs, il obtint l'absolution et l'indulgence pour lui et toute sa famille. Cette sévérité fut néanmoins tempérée par une compensation de 15 sous pour lui-même et de 5 sous pour son oncle Robert;

7. Vers 1131, comme l'abbé Bernard avait été béni par l'évêque d'Avranches Turgis, le camérier Roger demanda restitution de ce qui lui était échu par droit

31. Cartulary of Mont Saint-Michel, $\mathrm{n}^{\circ} 82-83$.

32. Carteret, Manche, cant. Barneville-Carteret.

33. Cartulary of Mont Saint-Michel, $\mathrm{n}^{\circ} 98$; cette notice est suivie par une autre dans le cartulaire consacrée à l'engagement d'une autre portion de l'église d'Huisnes (Cartulary of Mont SaintMichel, $\mathrm{n}^{\circ}$ 99), mais les deux affaires paraissent distinctes.

34. Huisnes-sur-Mer, Manche, cant. Pontorson.

35. Cartulary of Mont Saint-Michel, $\mathrm{n}^{\circ} 88$; cette affaire doit dater de 1140/1149, car les témoins, Ruellen canonicus, Guillelmus Pulchra Barba et Hugo Testa, sont caractéristiques de la fin de l'abbatiat de Bernard (1131-1149). 
héréditaire, à savoir des provendes à Noël et à Pâques ainsi que du fourrage quotidien pour deux chevaux. Peu après il entra en conflit avec l'abbé, mais récupéra ses revenus pour faire la guerre en Bretagne. Appauvri à son retour, il abandonna toute réclamation excessive et fit son hommage à l'abbé. Mais après la mort d'Henri I ${ }^{\text {er }}$, il rejoignit le camp des ennemis de la Normandie, se ligua avec des Bretons et après avoir ravagé les terres de l'Église, la vengeance divine s'abattant sur lui, il mourut excommunié, sans absolution, et son corps resta sans sépulture (après 1143) ${ }^{36}$.

Afin de justifier un jugement ou le plus souvent un compromis, sinon les deux, les moines réécrivaient des actions anciennes articulées par des conjonctions: tunc, rursum, postea, igitur... Les passages narratifs s'allongeaient avec le développement des affaires au cours du temps. L'exposé des motifs tend à s'amplifier en de très longs récits. Ils sont construits selon un scénario quasi-immuable et ordonnés par quelques situations-clés:

- Un ou des laïcs élèvent une réclamation (calumnia, $\left.\mathrm{n}^{\circ} 2,6\right)$ voire une véritable plainte (clamor, $\mathrm{n}^{\circ}{ }^{5}$ ) à l'encontre d'une transaction initiale (rappelée par l'extrait d'une charte, $\left.\mathrm{n}^{\circ} 1,2,4 \mathrm{a}, 5,6\right)$;

- L'abbé riposte par une clamor adressée au duc $\left(\mathrm{n}^{\circ} 1\right)$ ou à Dieu $\left(\mathrm{n}^{\circ} 3\right)$ à moins qu'il n'obtienne la reconnaissance «spontanée» de sa faute par le coupable faisant pénitence;

- Un judicium est parfois nécessaire $\left(\mathrm{n}^{\circ} 1,2,4 \mathrm{~b}\right)$, ce qui n'empêche d'ailleurs pas une transaction simultanée;

- Finalement l'affaire se conclut par un contre-don $\left(n^{\circ} 1,3,4 a, 6\right)$.

Le mode principal de résolution de ce type de conflits était donc la conciliation et la recherche d'un compromis créant un nouveau lien, souhaité plus stable, entre les parties. Les moines avaient intérêt à éviter l'affrontement direct qui bloquait la situation et entretenait le trouble. La repentance et le pardon étaient des éléments centraux de l'apaisement. L'échec créait l'inquiétude. La notice concernant Roger le camérier $\left(\mathrm{n}^{\circ} 7\right)$ est un texte purement narratif, reprenant la

36. Cartulary of Mont Saint-Michel, App. II, $\mathrm{n}^{\circ} 9 ; \mathrm{BnF}$, ms. lat. 5430A, $\mathrm{f}^{\circ} 270$ : cepisset illico Domini et archangeli Michaelis sagitta, percussus nec diutius vivens sine absolutione excommunicationis ecclesie est defunctus et iccirco sicut nunc usque apparet super terram jacet inhumatus. Hac occasione predictus Rogerus testimonio terre maris (?) que prescripta perdidit. Le camérier Roger figure dans des actes du cartulaire du Mont Saint-Michel entre 1128 et 1143 (Cartulary of Mont SaintMichel, $\left.\mathrm{n}^{\circ} 45,55,76,85\right)$. Les événements rapportés se déroulèrent durant une dizaine d'années. Roger le camérier était aussi un homme des vicomtes de Saint-Sauveur, possessionné à SaintSauveur-le-Vicomte et à la Colombe (Manche, cant. Percy; Delisle, Léopold, Histoire du château et des sires de Saint-Sauveur-le-Vicomte, Valognes, Martin, 1867, PJ, n 45, p. 54); il fut certainement un partisan d'Étienne de Blois, car Roger vicomte de Saint-Sauveur fut assassiné en 1138 au château du Homme/l'Isle-Marie par des hommes de Mathilde l'Emperesse (OrDERIC Vital, Ecclesiasticae historiae, XIII-36, éd. Marjory Chibnall, The ecclesiastical history of Ordericus Vitalis, Oxford, Clarendon Press, Oxford Medieval Texts, 1969-198o, t. VI, p. 511-513). En tant que comte de Mortain, Étienne avait dû se constituer de solides appuis à l'ouest de la Vire. Mais il perdit ce comté en 1141. Finalement, la notice montoise condamnait un partisan d'Étienne après que celui-ci eut perdu la Normandie. Sur les troubles aux confins de la Bretagne et de l'Avranchin durant cette guerre civile, voir DUfIEF, «La vie monastique au Mont Saint-Michel pendant le XII ${ }^{\mathrm{e}}$ siècle... », p. 97-99. 
structure des notices. Il est introduit par: «Nous souhaitons transmettre, par la digne mémoire des lettres, la raison pour laquelle le camérier Roger aura perdu tout ce qu'il avait justement et injustement possédé dans l'Église ${ }^{37} »$. Il fut apparemment rédigé à la seule fin de démontrer l'entière responsabilité de Roger dans l'issue particulièrement dramatique de cette affaire (il mourut sans avoir été réconcilié avec l'Église). La mort brutale du camérier n'ayant pas permis de nouvel arrangement intéressant la postérité, le texte ne fut pas copié dans le cartulaire. Mais l'absence de conventio maintenait l'affaire en suspens, embarrassant les moines qui cherchèrent néanmoins à justifier leur fermeté à l'égard de leur ancien fidèle. Ils se dotèrent ainsi du moyen d'étouffer toute réclamation ultérieure de la part des héritiers du camérier, ce qui aurait entretenu une faide. Le souci de l'abbé était autant de défendre les intérêts matériels de son église ${ }^{38}$, que de rétablir l'ordre social ${ }^{39}$ et de réintégrer le malfaiteur dans la société et dans l'Église, pour son salut ${ }^{40}$.

Dans le cas de Saint-Jean $\left(\mathrm{n}^{\circ} 3\right)$, les moines proposèrent d'emblée à un Thomas repentant, d'exposer les conditions de sa réconciliation ${ }^{41}$. Cette attitude n'était nullement un aveu de faiblesse puisque la seule issue proposée par l'abbé était la restitution des biens ${ }^{42}$. Malgré les tentatives d'intimidation de part et d'autre (construction d'un castellum et clamor liturgique), la solution recherchée était celle du compromis. Même lorsque l'abbé semblait avoir obtenu gain de cause, son entourage l'amenait à conclure un arrangement. Ainsi, les neveux de Jean fils de Garnier de Huisnes, « déboutés de leurs prétentions » par l'éloquence de l'abbé Bernard, obtinrent finalement les biens contestés contre un fermage annuel de vingt-deux sous, grâce à l'intervention de l'évêque d'Alet Donoald et de l'abbé de Saint-Sever Roger, présents à l'abbaye en raison des fêtes de la SaintMichel $\left(n^{\circ}{ }_{5}\right)$. Cette indulgence finale fut-elle l'expression de la miséricorde abbatiale ou bien les droits des deux requérants étaient-ils plus solides que ne l'avoue la notice du monastère? Quoi qu'il en ait été, le scénario paraît bien «huilé»: les scènes de la plainte et de l'indignation abbatiale, finalement fléchie par l'intervention de conciliateurs, étaient très ritualisées.

37. Cartulary of Mont Saint-Michel, App. II, $\mathrm{n}^{\circ}$ 9: De Rogerio camerario, memorie litterarum tradere dignum duximus qua ratione ipse perdiderit ea que in ecclesia sive juste sive injuste habebat [...]. L'acte ne recueillit ni souscription ni témoin.

38. Acta of William I, $\mathrm{n}^{\circ}$ 214, p. 674: Sepefato vero domno Rannulfo abbate haud enerviter obsistente, et tale prejuditium sancto Michaeli ac sibi illatum esse, regi suggerente, tandem in regali curia locus datus est discepandi [...].

39. Cartulary of Mont Saint-Michel, $\mathrm{n}^{\circ}$ 83, p. 159: Quo comperto liberales ipsius ville et ipsius provintie proceres super ignomina tanta confusi eos omino exterminaverunt et sacramento affirmaverunt ex tunc illos non recepturos nec cum eis deinceps habitaturos.

40. Cartulary of Mont Saint-Michel, $\mathrm{n}^{\circ}$ 88, p. 164: Insuper autem patrem meum et matrem et fratrem et omnes parentes meos et omnes coadjutores meos absolvere pecii quod et ipsi libenter fecerunt.

41. Cartulary of Mont Saint-Michel, $\mathrm{n}^{\circ}$ 16, p. 94: [...] pedibus abbatis donni Rogerii de Gemmetico et monachorum prostratus [...] ; Abbas [...] interrogans quo pacto et qua conditione ipse et fratres ejus Ecclesiae vellent reconciliari.

42. [...] quoniam nullo modo illos absolverent neque clamorem intermitterent nisi res et possessiones quas preocupaverant injuste omnino reliquerent. 
Le cadre de ces pourparlers était habituellement le chapitre abbatial. L'audience était élargie aux parents, aux amis voire aux proceres ou barones locaux $\left(\mathrm{n}^{\circ} 3,4\right)$. Mais aucune notice ne se réfère à un plaid ad hoc, autre que la curia regis $\left(\mathrm{n}^{\circ} 2\right)$. Le règlement paraît toujours fortuit. Des tiers intervenaient durant la négociation comme conseillers des parties en présence. Ils sont souvent évoqués par des formules lapidaires qui recouvrent la complexité des relations sociales: consilio fratrum suorum et procerum qui cum eo erant ou multis aliis baronibus $\left(\mathrm{n}^{\circ} 3\right) ;$ Dei inspiratione et amicorum suorum admonitione $\left(\mathrm{n}^{\circ} 4 \mathrm{~b}\right)$. Ces formules masquent le processus de conciliation, que les moines préféraient attribuer à la crainte de Dieu et à la très grande sagesse de leur abbé $\left(\mathrm{n}^{\circ} 5\right)$. De même, l'imputation de la faute à une inspiration diabolique ou au conseil d'hommes malveillants $\left(n^{\circ} 4 a\right)$ facilitait la réconciliation. Mais certaines notices sont plus précises, désignant des personnages d'autorité, comme un évêque $\left(\mathrm{n}^{\circ} 3,5\right)$, un abbé $\left(\mathrm{n}^{\circ}{ }^{\circ}\right)$ ou le comte $\left(n^{\circ} 2\right)$ mais aussi des parents, des frères $\left(n^{\circ} 3\right)$ ou un oncle maternel $\left(\mathrm{n}^{\circ} 6\right)$. Leurs fonctions de régulateurs et de «démineurs» étaient essentielles et ils étaient associés au règlement final, en tant que coadjutores $\left(\mathrm{n}^{\circ} 6\right)$. Dans ce "petit monde ${ }^{43}$ », les amis ou les parents qui conseillaient les laïcs étaient probablement aussi des proches du monastère et les rôles étaient interchangeables. D'abord accusé, Thomas de Saint-Jean devint conciliateur, obtenant que son frère, le "perfide" Roger, fasse hommage à l'abbé et devienne l'homme de l'abbaye ${ }^{44}$. Dans l'affaire de Poterel, l'abbé passa du rôle de victime et d'accusateur à celui d'intercesseur pour la réconciliation entre le meurtrier et le duc qui l'avait condamné à l'exil, en réponse à la clamor des moines ${ }^{45}$. En échange de son pardon et de son intercession, l'abbé obtint la confirmation de la vente par un serment. Dans la notice, la sentence ducale n'est finalement qu'une circonstance de la magnanimité de l'abbé. Mais on aimerait connaître les raisons qui poussèrent le vendeur à un véritable acte de faide : l'assassinat du porcher des moines dans le bois de Bevais ${ }^{46}$. Les moines n'avaient-ils pas rempli toute leur part du contrat de vente? La notice se garde bien de toute précision à ce sujet, de même qu'elle ne précise pas si le vendeur reçut une autre compensation que la fin de son exil. Mais par son revirement, l'abbé chercha à interrompre cette faide $^{47}$. L'alternance des rôles de Thomas (agresseur/dénonciateur de la perfidie

43. Expression empruntée à Wendy Davies (DAvies, Wendy, Small worlds. The village community in early medieval Brittany, Londres, Duckworth, 1988).

44. Cartulary of Mont Saint-Michel, $\mathrm{n}^{\circ} 16$, p. 95 : Guillelmus de Pomeria (Saint-Sauveur-la-Pommeraye, Manche, cant. Bréhal) et Stephanus de Tabula (n.i.) submiserunt se ut perfidi Rogerio fratri meo, cui consulo et laudo ut pro illorum servitio vobis hominium faciat et sit hujus ecclesie homo [...].

45. RADN, $\mathrm{n}^{\circ}$ 232, p. 447-448: [...] ipse Rogerius extermunum (sic) ferre non valens perinter nuntios multociens abbatem requisivit mandans et multum deprecans ut cum duce Normanniae ei pacem reformaret sibique conciliari permitteret [...].

46. RADN, $\mathrm{n}^{\circ} 232, \mathrm{p} .447:[\ldots]$ post multum vero temporis isdem Rogerius instigante diabolo quadam die in nemore de Bivie porcos Sancti Michaelis inveniens fraudulenter et nequiter subulcum interfecit.

47. Sur ce type de conflits et la «société faidale», voir BARThéLemy, Dominique, «La vengeance, le jugement et le compromis», in Le règlement des conflits au Moyen Âge, Paris, 2001, p. 11-20; ID., Chevaliers et miracles. La violence et le sacré dans la société féodale, Paris, Armand Colin, 2004. 
de son frère/conciliateur) et de l'abbé Renouf (victime/accusateur/intercesseur) suit la succession des phases de ce type de conflits entre des moments d'intense violence (meurtre) et d'apaisement.

La grande majorité des notices ne présentent pas ces intercesseurs comme des arbitres désignés selon une procédure légale et leur rôle se distingue mal de celui des témoins convoqués par les parties ou des simples observateurs (qui auront vu et entendu pour la postérité). Deux notices classent cependant les assistants selon les parties $\left(\mathrm{n}^{\circ} 4 a, 6\right)$. La composition des listes de souscripteurs ou/ et de témoins est variable: leur nombre est compris entre 5 et 25 et leur dignité varie selon le rang social des protagonistes et l'objet de la querelle. Les adversaires des moines sont souvent absents $\left(\mathrm{n}^{\circ} 1,2,4 \mathrm{~b}\right)$ : soit qu'ils aient été condamnés $\left(n^{\circ} 4 \mathrm{~b}\right)$, soit que le document conservé par les moines ait été produit à charge et qu'il ne s'agisse pas d'une conventio $\left(\mathrm{n}^{\circ} 2\right)$. Deux des trois notices qualifiées de pactum $\left(\mathrm{n}^{\circ} 3\right.$, 4a) sont dûment souscrites par les deux parties ${ }^{48}$. Le dénominateur commun entre tous les groupes de souscripteurs et de témoins est la forte représentation des membres de la familia abbatiale, ce qui est une indication sur le caractère interne des affaires en question.

Pourtant, certaines d'entre elles requirent les participations d'autorités extérieures, ducale ou épiscopale $\left(\mathrm{n}^{\circ} 1,2,3,4 \mathrm{a}\right)$. Mais la nature exacte de ces participations est rarement explicitée. Dans l'affaire de Poterel $\left(\mathrm{n}^{\circ} 1\right)$, le duc répondit «immédiatement», suae majestatis, à la clamor abbatiale par l'exil du coupable. La tournure criminelle prise par les événements explique cette procédure, qui n'empêche d'ailleurs pas la conciliation ultérieure. Les interventions de Guillaume en tant que duc puis roi, à propos du moulin de Vains $\left(n^{\circ} 2\right)$, sont ambiguës, car il était aussi le fils de l'auteur de l'aumône contestée, qu'il se contentait de confirmer. Par la vente de cette aumône ducale, l'abbé Suppo avait bafoué la mémoire du bienfaiteur, le duc Robert le Magnifique. On peut se demander si la procédure exceptionnelle décrite par la notice ne fut pas déterminée par la qualité des protagonistes: l'examen par la curia ducale et la désignation de judices pourvus d'une délégation d'autorité sont attestés par le diplôme et la notice ${ }^{49}$. À Carteret $\left(\mathrm{n}^{\circ} 4 \mathrm{a}\right)$, les souscriptions de l'évêque de Coutances Algare, du doyen de Bayeux, de trois archidiacres et d'un chantre au bas d'un accord (donum) passé coram capitulo rappellent certainement que ces dignitaires prirent une part active dans le règlement de ce conflit relatif au droit de patronage sur l'église paroissiale de Saint-Germain de Carteret ( $\left.{ }^{\circ} 4 a\right)$. Au début

48. Dans la cas de la troisième $\left(\mathrm{n}^{\circ}\right.$ 5) la situation est moins claire. En effet, les deux bénéficiaires de la ferme de l'église de Huisnes sont simplement désignés comme les neveux du donateur, l'un clerc, l'autre laïc. L'attribution à ferme de l'église de Huisnes se présente comme une libéralité de l'abbé. Mais il est possible qu'ils figurent parmi les témoins de la notice (Cartulary of Mont Saint-Michel, $\mathrm{n}^{\circ}$ 98, p. 172). Parmi ceux-ci Ilgerius de Vesce et Jean Chesnel portent les mêmes noms que le donateur, Jean fils de Garnier de Huisnes et son frère Ilgerius.

49. RADN, $\mathrm{n}^{\circ} 148$ A2, p. 332, 1061; Acta of William I, $\mathrm{n}^{\circ}$ 214, p. 674: il s'agissait de l'évêque de Coutances Geoffroi, delegatus regali auctoritate discussor et judex, du vicomte Renouf, de Néel fils du vicomte Néel et de Robert de Vezpunt. 
du XII e siècle, l'autorité des évêques sur les transferts d'églises paroissiales était pleinement reconnue.

Le roi Henri I ${ }^{\text {er }}$ ne joua apparemment aucun rôle dans le différend opposant Thomas de Saint-Jean à l'abbaye $\left(\mathrm{n}^{\circ} 3\right)$. Il se serait contenté de souscrire à Argenteium/Arganchy ${ }^{50}$ le testamentum établi à la suite du pactum conclu entre eux. Deux raisons peuvent justifier l'intervention royale: la qualité du seigneur de Saint-Jean et l'objet de la dispute. La villa de Saint-Jean supra mare figure pour la première fois dans la documentation comme une aumône ducale ${ }^{51}$. Puis son seigneur Raoul de Saint-Jean attesta deux diplômes ducaux parmi les hommes de saint Michel ${ }^{52}$. Selon Wace, il aurait participé à la conquête de l'Angleterre ${ }^{53}$. Thomas et ses frères furent élevés et nourris à l'abbaye du Mont Saint-Michel ${ }^{54}$. Thomas lui-même commandait une avant-garde de l'armée d'Henri I ${ }^{\text {er }}$ à la bataille de Tinchebray en $1106^{55}$. Il était shérif d'Oxfordshire $(1111)^{56}$ et tenait des biens dans le Sussex ${ }^{57}$. Les trois frères conduisirent des opérations militaires normandes aux confins de la Normandie et du Maine ${ }^{58}$, ce qui valut à Thomas une période d'emprisonnement à Gorron ${ }^{59}$. Il s'associa aux fondations des proches du roi à Saint-Sever ${ }^{60}$, au Neubourg près de Mortain (l'Abbaye Blanche)

50. Arganchy, Calvados, cant. Bayeux. Jacques Boussard avait proposé Argentan comme lieu de cette confirmation. Mais, un acte d'Henri ${ }^{\text {er }}$ de 1118 en faveur de l'Abbaye Blanche est lui aussi daté d'Argenteium identifié à Arganchy par ses éditeurs successifs (JoHnson, Cronne, Regesta regum anglo-normannorum 1066-1154, t. II, $\mathrm{n}^{\circ}$ 1183/1184). Le roi fit plusieurs séjours à Arganchy: en 1120 ( ibidem, $\mathrm{n}^{\circ}{ }_{1224}$ ), en 1126/1129 (ibidem, $\mathrm{n}^{\circ}$ 1589-1590-1592), en 1133/1135 (ibidem, $\mathrm{n}^{\circ}{ }^{1898}$ 1899). D'ailleurs, Auguste Longnon a relevé pour Argentan les formes suivantes, Argenthomum ou Argentomum et pour Arganchy, Arguencheyum, plus proche de l'acte étudié (Longnon, Auguste, Pouillés de la province ecclésiastique de Rouen, Paris, Imprimerie nationale, 1903, p. 390). Cette résidence située entre Bayeux et l'abbaye de Saint-Vigor de Cerisy, fondée par Robert le Magnifique ( $\left.R A D N, \mathrm{n}^{\circ} 64, \mathrm{p} .192-195\right)$, était déjà un lieu de pouvoir pourvu d'un bourg sous le règne de Guillaume le Bâtard (RADN, $\left.\mathrm{n}^{\circ} 167, \mathrm{p} .358-359\right)$.

51. RADN, $\mathrm{n}^{\circ} 49$, p. $161,1025 / 1026$.

52. RADN, $\mathrm{n}^{\circ} 133$, p. 308, 25 décembre 1053/1054 et $R A D N, \mathrm{n}^{\circ} 232, \mathrm{p} .448,1066$.

53. Wace, Le roman de Rou, éd. Anthony John Holden, Paris, Picard, Société des Anciens textes français, 1970-1973, t. II, p. 202, $3^{\mathrm{e}}$ partie, v. 8512; VAN Houts, Élizabeth M.C., «Wace as historian", in Family trees and the roots of the politics: Britain and France from the tenth to the twelfth century, Katharine S. B. Keats-Rohan (éd.), Woodbridge, 1997, p. 129, nº 86.

54. Cartulary of Mont Saint-Michel, $\mathrm{n}^{\circ}$ 16, p. 95 : [...] quia nolumus minuere debita et consuetudines hujus sancte ecclesie cujus beneficio et nutrimento educati et procreati sumus [...].

55. Orderic Vital, Ecclesiasticae Historiae, XI-20, éd. Marjory Chibnall, The ecclesiastical history..., t. VI, p. 84-85.

56. Green, Judith, The government of England under Henry I, Cambridge, Yale University Press, 1986, p. 147-148.

57. Regesta Henrici Primi, ${ }^{\circ}$ 885-897-958; Warren Hollister, Charles, Henry I, Londres, Yale University Press, 2001, p. 59.

58. Ils commandaient 140 chevaliers en 1118 (OV, XII-4, t. VI, p. 194-196).

59. Cartulary of Mont Saint-Michel, $\mathrm{n}^{\circ}$ 16, p. 96.

60. Thomas fut un bienfaiteur de l'abbaye de Saint-Sever fondée par Hugues le Loup, vicomte d'Avranches et comte de Chester (Musset, Lucien, «Les origines et le patrimoine de l'abbaye de Saint-Sever », in La Normandie bénédictine au temps de Guillaume le Conquérant, Lille, 1967, p. 362). 
et à Savigny ${ }^{61}$. De plus, la construction d'un château que le roi reprit ensuite ${ }^{62}$, les services de chevaliers des hommes de ce secteur frontalier ainsi que l'hommage de Thomas à l'abbé intéressaient le roi. L'abbaye jouait un rôle militaire important dans le secteur, comme l'attestent une notice de convention fixant ses relations avec Guillaume Paisnel ${ }^{63}$ ainsi que l'enquête de 1172 sur les services de chevaliers dus au roi, à l'abbaye ${ }^{64}$. Enfin, Henri I $^{\text {er }}$ intervint directement dans la vie montoise durant son règne ${ }^{65}$. Il se pourrait donc que le roi ait arbitré la querelle dès le début, ce qui expliquerait la contrition rapide de Thomas. D'ailleurs, ne devrait-on pas discerner une manœuvre royale, visant à la réorganisation militaire du secteur, derrière les "ravages et les usurpations» du seigneur châtelain de Saint-Jean? L'abbé Roger ne dénonça pas la construction du château en elle-même, mais la destruction consécutive des bois voisins, dont le sort fit l'objet d'un second accord. Le bois de Bevais relevait depuis toujours de la villa de Saint-Jean ${ }^{66}$ et Thomas reconnut devoir annuellement à l'abbaye, pour celuici, 20 sous manceaux à la foire de Montmartin-sur-Mer. En 1172, Guillaume de Saint-Jean, neveu de Thomas, conclut avec l'abbé du Mont Robert de Torigni un accord lui reconnaissant, par droit héréditaire, la forestaria (il percevait la moitié des revenus des plaids la concernant) sur cette forêt et ses landes ${ }^{67}$.

61. Van Moolenbroek, Jaap, Vital l'ermite, prédicateur itinérant, fondateur de l'abbaye normande de Savigny, Maastricht, 1990, trad. Anne-Marie Nambot, Revue de l'Avranchin et du Pays de Granville, mars 1991, t. LXVIII, $\mathrm{n}^{\circ} 346$, p. 257-274, $\mathrm{n}^{\circ} 3$ (1113, confirmation de la fondation par Henri $\left.\mathrm{I}^{\mathrm{er}}\right), \mathrm{n}^{\circ} 6(1118), \mathrm{n}^{\circ} 10$ et 11 (1112).

62. Robert De Torigni, Chronique suivie de divers opuscules historiques de cet auteur, éd. Léopold DelisLe, Rouen, Société de l'histoire de Normandie, 1872-1873, t. I, p. 196-197, n. 5; Yver, Jean, «Les châteaux forts en Normandie jusqu'au milieu du XII siècle», BSAN, t. LIII, 1957, p. 97, n. 150 .

63. Cartulary of Mont Saint-Michel, $\mathrm{n}^{\circ}$ 90, Conventio inter abbatem et Guillelmum Paginellum; Navel, Henri, Recherches sur les institutions féodales en Normandie (région de Caen), Caen, BSAN, 1951, p. 36 et Haskins, Charles Homer, Norman Institutions, Cambridge, Harvard University Press, 1918 (rééd. 1960), p. 21: accord passé à la cour du roi vers 1071/1081, entre Guillaume Paisnel et l'abbaye, lors du mariage de celui-ci. Il prévoit les détails des devoirs et obligations réciproques comme avec Thomas de Saint-Jean. Sur la critique de ce texte, voir BATES, David, Normandy before 1066, Londres, Longman, 1982, p. 258-259.

64. Cartulaire du Mont Saint-Michel, Bibl. mun. Avranches, ms. 210, $\mathrm{f}^{\circ} 132 \mathrm{v}^{\circ}$.

65. L'un des actes est daté d'après son règne (Cartulary of Mont Saint-Michel, $\mathrm{n}^{\circ} 76$, Carta de Sartilleio); plus significatif, vers 1123/1129, le roi procède à l'échange du manoir de Budleigh (co. Devon) en Angleterre contre les églises de Wargraveet de Cholsey/Cheals (co. Berkshire) (Cartulary of

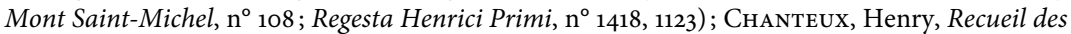

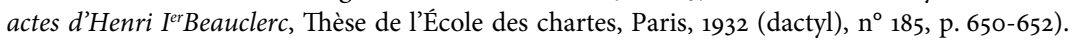
Le roi procéda à la mutation ou à la désignation de quatre abbés: Roger I ${ }^{\text {er }}$, Roger II, Richard de Mere et Bernard (DufIEF, «La vie monastique au Mont Saint-Michel pendant le XII siècle...», p. 82-99; GAZEAu, Prosopographie des abbés bénédictins..., p. 172-175).

66. $R A D N, \mathrm{n}^{\circ} 73$, p. $213,1027 / 1035$ : [...] villam quae dicitur Sancti Johannis, sitam supra mare, cum omnibus ad eam pertinentibus, silvam quoque quae dicitur Bivia cum silvulis quibusdam aspicientibus ad eam [...].

67. Robert de Torigni, Chronique..., t. II, p. 303-305; Delisle, Léopold, Berger, Elie, Recueil des actes d'Henri II roi d'Angleterre et duc de Normandie concernant les provinces françaises et les affaires de France, Paris, 1909-1927, t. I, n ${ }^{\circ}$ CCCCXLVIII, p. 579-580. 
Les rapports sociaux au sein de la seigneurie du Mont Saint-Michel constituaient l'enjeu véritable de la querelle. Thomas provoqua ce conflit, non par "esprit d'indépendance», mais afin de clarifier les liens de son lignage avec l'abbaye ${ }^{68}$ : l'abbé reçut son hommage et celui de son frère. Lui et ses frères cherchaient à s'intercaler entre l'abbé et les hommes tenus au service militaire à l'abbaye, en distinguant leurs parents des autres vavasseurs ${ }^{69}$. Dans cette redéfinition triangulaire (l'abbaye, le roi et Thomas) des rapports sociaux, le château était un gage essentiel de la crédibilité de Thomas et de ses frères. L'ascension sociale de la famille de Saint-Jean doit se replacer dans le contexte de la promotion de nombreux lignages de Normandie occidentale, notamment du Cotentin, après les succès d'Henri Beauclerc comte du Cotentin (1088-1101), puis roi d'Angleterre en 1100 et duc de Normandie en 1106.

Deux affaires allèrent jusqu'à des sentences unilatérales, appelées judicium, délivrées lors de plaids $\left(\mathrm{n}^{\circ} 2-4 \mathrm{~b}\right)^{70}$. Le judicium était un ultime recours pour les moines et apparaît surtout comme un échec des autres moyens de rétablir l'ordre social et les droits abbatiaux. Les deux premières tentatives de conciliation du différend opposant l'abbaye aux habitants de la villa de Carteret, à propos des «mauvaises coutumes» touchant à la perception de la dîme $\left(\mathrm{n}^{\circ} 4 \mathrm{~b}\right)$, restèrent infructueuses. Alors l'abbé réunit une curia dans laquelle siégèrent les liberales de la villa ainsi que les proceres de la province. Les accusés s'étant dérobés au judicium (confirmant sans doute les droits revendiqués par l'abbaye), les liberales et les proceres leur infligèrent une sentence d'exil ${ }^{71}$. Dans l'affaire du moulin de Vains $\left(n^{\circ} 2\right)$, la notice spécifie que Jean fils de Richard ignora volontairement les preuves produites par l'abbé, contraignant celui-ci à porter l'affaire in regali

68. Pour une approche anthropologique des conflits et leur fonction structurelle dans la société médiévale, voir Geary, Patrick J., "Vivre en conflit dans une France sans État: typologie des mécanismes de règlement des conflits (1050-120o)», Annales ESC, t. 41, 1986, p. 1107-1133.

69. Cartulary of Mont Saint-Michel, $\mathrm{n}^{\circ}$ 16, p. 94: [...] illorum hominum servitium michi fratribusque meis concedite qui carnis propinquitate nobis conjuguntur, excepta Montis custodia, et de hominibus illorum habeatis moltam, theloneum, taillas, auxilia et cetera servitia que juste majori domino debentur; solummodo mihi servitia militum concedantur, et ego servicia vobis faciam et cetera cuncta vobis remaneant. Les vavasseurs de la fin du $\mathrm{XI}^{\mathrm{e}}$ siècle étaient une catégorie sociale qui avait hérité des homines liberi des compétences dans les institutions publiques judiciaires et militaires, dans lesquelles ils agissaient comme jurés et servants à cheval. Ils avaient en outre la responsabilité de la gestion paroissiale, c'est-à-dire la perception des dîmes et l'entretien de l'église (Arnoux, Mathieu, Mémoire, travail et structures communautaires. Étude sur la société des campagnes normandes ( $X^{e}-X V I^{e}$ siècles), Mémoire d'habilitation, Paris, 1997 (dactyl.), p. 5966).

70. BARthéLemy, La société dans le comté de Vendôme..., p. 660-666. Il est question, dans un troisième texte $\left(\mathrm{n}^{\circ} 1\right)$, d'une sentence d'exil prononcée par le comte, à l'encontre d'un meurtrier $\left(R A D N, \mathrm{n}^{\circ} 232, \mathrm{p} .447\right)$ : Comes autem continuo ipsum Rogerium ut suae majestatis reum a totius Normanniae patria eliminavit.

71. Cartulary of Mont Saint-Michel, $\mathrm{n}^{\circ}$ 83, p. 159: harangue de l'abbé et serment de fidélité des contrevenants; Ad ultimum congregata curia ad dies plurimos constitutos omne juditium subterfugeret et sic malicia eorum comperta omnibus patuit. Quo comperto liberales ipsius ville et ipsius provincie proceres super ignominia tanta confusi eos omnino exterminaverunt et sacramento affirmaverunt ex tunc illos non recepturos nec cum eis deinceps habitaturos. 
curia qui arrêta (diffinire) un judicium légal ${ }^{72}$. Le duc-roi et ses juges ne prononcèrent pas de condamnation mais se contentèrent de confirmer la propriété de l'abbaye en échange d'un contre-don ${ }^{73}$. Ils fournissaient ainsi à l'abbé une preuve de la justesse de sa cause, mais lui laissaient le soin de négocier des arrangements ${ }^{74}$. Or, l'abbé Renouf dut racheter le moulin à Waleran et à sa parenté, contre un prix «non négligeable ${ }^{75}$. Ainsi les formules martiales de la notice du plaid ducal, rédigée sur le modèle d'un diplôme solennel, ne reflètent pas la réalité des tractations et des compositions. Malgré la mise en scène de l'autorité ducale, le judicium permit au mieux d'accélérer la conclusion d'une transaction «privée». D’ailleurs, de quel côté était le droit? Les financiers qui avaient traité avec l'abbé Suppo n'avaient pas été malhonnêtes. En conséquence, ils ne pouvaient être condamnés au nom de normes juridiques préétablies ${ }^{76}$. En revanche, cette affaire fut exploitée contre l'abbé Suppo, nommé à la tête de l'abbaye par le duc Robert le Magnifique et qui dut affronter l'hostilité des moines ${ }^{77}$. La procédure judiciaire, par laquelle Guillaume le Bâtard désavouait la gestion d'un abbé nommé par son père, venait clore une période de plusieurs décennies de conflits internes à l'abbaye.

Ces sentences n'étaient pratiquement jamais pénales, surtout lorsqu'elles intervenaient dans des conflits entre pairs. Les notices de plaid n'avaient pas vocation à prononcer des peines, ce qui montre bien que la répression n'était pas le but principal de cette justice. Les deux judicia du duc-roi Guillaume étaient destinés à prouver le droit de l'abbaye par la réitération d'une confirmation. Ils

72. Acta of William I, $\mathrm{n}^{\circ}$ 214, p. 674: [...] Johannes filius Ricardi conatus est eidem sancto archangelo calumpniam struere, et qualiter eidem calumpniatio oppressa sit justo judicio optimatum patriae breviter annectere $[\ldots] ;[\ldots]$ plures judices ample opinionis qui diligenter et ad unguem disquirentes originem contentionis, legali judicio diffinierunt [...]. Le rédacteur de cette notice s'attacha particulièrement à reproduire les documents originaux ( $\mathrm{cf}$. infra) et à décrire la procédure judiciaire par un vocabulaire technique approprié. Toutefois, la description de cette procédure est unique dans les documents montois. Dans cette série de textes, judicium est synonyme de diffinitum ( $\left.R A D N, \mathrm{n}^{\circ} 148 \mathrm{~A} 2\right)$ et de diffinitio.

73. RADN, $\mathrm{n}^{\circ} 148 \mathrm{~A} 1, \mathrm{p} .331$ : une charte très brève enregistrant, en présence du cubicularius Raoul, le dédommagement ducal de 30 livres.

74. Laurent Morelle aboutit à des conclusions concordantes à propos d'un dossier concernant l'avouerie de Corbie vers 1042/1055: les moines y traitent par négociation et misent sur l'engagement du délinquant, ravalant la sanction royale au rang de force d'appoint (MorelLE, Laurent, «Les chartes dans la gestion des conflits (France du nord, XI'-début du XII ${ }^{e}$ siècle)», in Pratiques de l'écrit documentaire au XI siècle, Guyotjeannin, Olivier, Morelle, Laurent, Parisse, Michel, (éd.), Paris [Bibliothèque de l'École des chartes, t. 155], 1997, p. 280).

75. Acta of William I, $\mathrm{n}^{\circ}$ 214, p. 673: [...] Rannulfi abbatis temporibus idem molendinum Gualeranus filius Ranulfi optinuit ceteris suae parentelae multipliciter deficientibus a quo prefatus domnus abbas Ranulfus non minimo pretio illud redemit [...]. Les textes ne disent pas ce qu'il advint des droits de Jean fils de Richard vers 1076.

76. Sur le statut juridique de la tenure en aumône, voir YvER, Jean, «Une boutade de Guillaume le Conquérant. Note sur la genèse de la tenure en aumône», in Études d'histoire du droit canonique dédiées à Gabriel le Bras, Paris, p. 78-796.

77. Le règlement de l'affaire fut peut-être facilité par la mort de l'ex-abbé Suppo, en 1061; LAPORTE, Jean, «L'abbaye du Mont Saint-Michel aux X $\mathrm{X}^{\mathrm{e}}$ et $\mathrm{XI}^{\mathrm{e}}$ siècles", in Millénaire monastique du Mont Saint-Michel, t. I, Histoire et vie montoise, Paris, 1967, p. 74-77; GAZEAU, Prosopographie des abbés bénédictins..., p. 166-169. 
validaient l'argumentaire des moines, reposant sur des actes écrits. Les excommunications ${ }^{78}$ ou les exils y étaient rappelés parmi les circonstances des conventiones mettant fin à leur application. Les peines étaient des instruments de la négociation jusqu'au moment où un pactum interrompait momentanément le cycle des calumniae et des clamores. Une sanction définitive aurait, au contraire, risqué d'entretenir ou d'envenimer la querelle, en entretenant le cycle de la vengeance $^{79}$. Seul un compromis admis par les parties permettait d'éteindre une querelle, car les héritiers reprenaient les revendications de leurs aïeux, entretenant les conflits durant plusieurs générations. L'exception notable de la condamnation des habitatores de Carteret $\left(\mathrm{n}^{\circ} 4 \mathrm{~b}\right)$ s'explique par le statut social des contradicteurs de l'abbé. Il ne s'agit pas d'un conflit entre égaux, d'une banale calumnia, mais d'une conspiratio ${ }^{80}$. L'issue d'une «telle ignominie ${ }^{81} »$ ne pouvait être qu'une victoire totale de l'abbaye, soutenue par les vavasseurs et les puissants de la province. Les accents particulièrement vindicatifs de cette notice expriment l'intensité des tensions entre les seigneurs et les paysans du duché ${ }^{82}$.

Le style documentaire de la notice n'accompagna donc pas des changements dans les procédures judiciaires, consécutives à l'affaiblissement du pouvoir princier. Les notices ne jalonnent pas les périodes de défaillance de l'autorité ducale, exposant l'abbaye aux prétentions laïques et contraignant des abbés réduits à leurs seules forces à transiger. Le pouvoir d'Henri Ir n'est pas en crise dans la région vers 1120. A contrario, le diplôme ducal de 1061 ou la notice de 1076 ne sont pas davantage le reflet d'une justice ducale sûre d'elle-même, mais une manifestation du soutien ducal à l'abbaye dans la négociation engagée. Les deux types documentaires conservent leurs propres parts d'ombre sur les conditions

78. L'excommunication n'est évoquée que par deux textes du corpus $\left(\mathrm{n}^{\circ} 6,7\right)$ et s'accompagne d'une pénitence beaucoup plus lourde du coupable. Outre l'exemple du camérier Roger $\left(\mathrm{n}^{\circ} 7\right)$, celui de Robert Malmarche, excommunié mais réconcilié in extremis sur son lit de mort (Cartulary of Mont Saint-Michel, $\mathrm{n}^{\circ}$ 88, p. 164): Rotbertus calumpniaverat et per multos annos excommunicatus usque ad obitum suum possedit tandem in semet reversus viamque universe carnis se iturum intelligens quod male et nequiter egerat emendare festinans quibusdam monachis qui ibi presto aderant prefatam terram reddidit [...]. Puis son fils Richard, excommunié à son tour et fouetté par le prieur devant l'autel de saint Michel (Cartulary of Mont Saint-Michel, $n^{\circ}$ 88, p. 164): [...] ante altare nudus in terram prostatus ac virgarum verbere nudus disciplinatus ab priore et monachis indulgentiam et absolutionem hujus insipientie mee gratia Dei patrocinante promerui.

79. Gauvard, Claude, "Conclusion", in Le règlement des conflits au Moyen Âge, Paris, Publications de la Sorbonne (Collection Histoire ancienne et médiévale, 62), 2001, p. 369-391.

80. Cartulary of Mont Saint-Michel, $n^{\circ}$ 83, p. 159: Post mortem enim karissimi notri Henrici regis in abbatem dominum suum et contra totius ville salutem nequiter compluribus hujusce mali consciis conspirationem fecerunt.

81. Ibidem: Quo comperto liberales ipsius ville et ipsius provintie proceres super ignominia tanta confusi eos omnino exterminaverunt [...].

82. Arnoux, Mathieu, "Classe agricole, pouvoir seigneurial et autorité ducale. L'évolution de la Normandie féodale d'après le témoignage des chroniqueurs ( $\mathrm{X}^{\mathrm{e}}-\mathrm{XII}{ }^{\mathrm{e}}$ siècles) ", Le Moyen Âge, $\mathrm{n}^{\circ}{ }^{1}$, 1992, p. 35-60. 
réelles de règlement de ces conflits. Les uns et les autres doivent être lus entre les lignes.

Auteurs d'une tradition écrite affirmant l'autonomie de l'abbaye à l'égard de l'autorité princière, les moines ne furent pas enclins à reconnaître leurs dettes envers elle. Leurs notices étaient principalement argumentatives. Ils y présentaient leurs preuves et étaient davantage portés à valoriser l'action de leurs abbés, qu'à décrire en détail les procédures judiciaires. Mais la présence royale est beaucoup plus forte dans les archives d'autres abbayes des diocèses de Coutances et d'Avranches. Henri était très proche de Montebourg, pour laquelle il délivra de nombreux brefs soigneusement conservés par les moines et reproduits dans leur cartulaire ${ }^{83}$, il était aussi très proche de Savigny ${ }^{84}$ ou de Lessay ${ }^{85}$ dont il confirma régulièrement les patrimoines. Ainsi les notices narratives du Mont Saint-Michel contribuèrent à une mise à distance, plus symbolique que réelle, de l'autorité ducale. Ces notices, dans lesquelles le prince n'intervenait que de manière lointaine, prouvaient d'une certaine manière la capacité du monastère à se protéger avec ses propres armes et justifiaient sa revendication d'autonomie ${ }^{86}$. La faible proportion de diplômes ducaux dans les archives montoises s'expliquerait davantage par un «choix éditorial» du scriptorium et l'élargissement du champ de l'écrit conservé, que par un éloignement effectif de l'autorité royale.

\section{L'écrit dans la résolution des conflits}

La référence à des écrits antérieurs est une constante: cinq notices sur sept débutent par la reprise d'une charte initiale. Il s'en faut cependant de beaucoup que chaque épisode rapporté soit associé à un acte écrit. La condamnation de Roger de Poterel par Guillaume le Bâtard $\left(\mathrm{n}^{\circ} 1\right)$ ou les excommunications de Robert Malmarche et de son fils Richard $\left(\mathrm{n}^{\circ} 6\right)$ n'apparaissent pas consignées dans des sentences écrites. Le rapport des négociations entre Thomas de SaintJean et l'abbaye $\left(\mathrm{n}^{\circ} 3\right)$ décrit une procédure uniquement orale transcrite à la fin pour corroboration. À l'inverse, l'argumentaire des moines concernant leur possession du moulin de Vains $\left(\mathrm{n}^{\circ}\right.$ 2) se fonde sur trois documents écrits, existants

83. BeARMAn, Robert, Charters of the Redvers family and the earldom of Devon 1090-1217, Exeter, Devon and Cornwall Record Society, 1994, $\mathrm{n}^{\circ}$ 5, p. 57-59, $1^{\mathrm{er}}$ août 1107; BnF, ms. lat. 10087, f ${ }^{\mathrm{o}} 7-8$; Haskins, Charles Homer, Norman Institutions, ${ }^{\circ} 8$, 9, 10, 11, 12, 13, 14, 15, p. 101-102, série de brefs datés de $1108 / 1135$.

84. Regesta Henrici Primi, $\mathrm{n}^{\circ} 1003$ (4 novembre 1112), 1015-1016 (2 mars 1113), 1183 (octobre 1118), 1212 (25 décembre 1119), 1433 (octobre 1125), 1588 (1129), 1973 (1123/1125).

85. Gallia Christiana, t. XI, Instrumenta, Ecclesiae Constantiensis, $\mathrm{n}^{\circ} \mathrm{X}$, col. 235-236; Regesta Henrici Primi, $\mathrm{n}^{\circ}$ 1441, éd. $\mathrm{n}^{\circ}$ CLXXVII, p. 353-354, confirmation générale en faveur de Lessay (1126); ibidem, $\mathrm{n}^{\circ} 1442$.

86. Cette remarque pourrait s'appliquer aux pancartes de l'abbaye de Saint-Sauveur-le-Vicomte (Delisle, Histoire du château..., PJ, $\mathrm{n}^{\circ} 45,46,48$, 50, p. 50-68) qui valorisèrent l'action des patrons laïcs successifs, les vicomtes Nigellides (VAN ToRHOUdT, Éric, "Les lieux de pouvoir des Néel, vicomtes dans le Cotentin", in Les lieux de pouvoir en Normandie et sur ses marges, Caen [Publications du CRAHM, $\mathrm{n}^{\circ}$ 2], 2006, p. 7-35), mais ne conservèrent qu'un seul diplôme jusqu'au règne d'Henri II (Acta of William I, $\mathrm{n}^{\circ} 260$, p. 784-785). 
ou supposés, dont l'un est même intégralement copié. Les situations apparaissent ainsi très contrastées, mais un examen plus détaillé, au-delà des choix narratifs, permet de les rapprocher. La question n'est donc pas celle de l'existence effective de l'écrit, mais plutôt celle de son usage et de sa valeur probatoire.

Le premier usage de l'écrit est bien sûr la rédaction des notices elles-mêmes. Il n'existe pas de style propre aux notices narratives qui sont des développements des chartes et des diplômes. Le formulaire particulièrement développé de la notice du moulin de Vains $\left(\mathrm{n}^{\circ} 2\right)$ est emprunté au style des diplômes normands du règne de Guillaume le Conquérant ${ }^{87}$, tandis que les autres récits sont encadrés par des formulaires réduits:

- L'invocation, In nomine Patris et filii et Spiritus Sancti, Amen [...] ( $\left.{ }^{\circ} 1,4 \mathrm{a}\right)$, s'est simplifiée après 1060/1066 par la suppression de sancte et individue Trinitatis $\left(\mathrm{n}^{\circ} 2\right.$ reprenant un diplôme de 1061, A2), mais elle tend à disparâ̂tre après $1130\left(\mathrm{n}^{\circ} 3,5,6\right)$;

- La notification varie: à tous ceux (ou seulement les moines, $\mathrm{n}^{\circ} 6$ ) présents et à venir $\left(n^{\circ} 1,3\right)$ ou bien à tous les fils de la sainte Église de Dieu $\left(n^{\circ} 5\right) \operatorname{tant}$ aux puissants qu'aux humbles ( $\mathrm{n}^{\circ} 4$, tam prelatis quam subditis);

- Les clauses finales débutent le plus souvent par un engagement personnel et une injonction aux héritiers de respecter le dispositif $\left(\mathrm{n}^{\circ} 1,3,6\right)$, appelé soit conventio $\left(\mathrm{n}^{\circ} 1,5\right)$, soit pactum $\left(\mathrm{n}^{\circ} 3,5\right)$ ou plus simplement qualifié de donum et concessum ( $\left.\mathrm{n}^{\circ} 4 \mathrm{a}\right)$ voire de redditio $\left(\mathrm{n}^{\circ} 6\right)^{88}$; cette injonction s'accompagne parfois d'une formule comminatoire $\left(n^{\circ}{ }_{1}\right)$ ou imprécatoire $\left(n^{\circ} 6\right)$; mais elle n'est pas systématique et se limite aussi au rappel de la perpétuité de l'accord (absente des $n^{\circ} 2,4 \mathrm{~b}, 5$ );

- Enfin le dispositif s'achève sur l'annonce d'une corroboration par des croix et des signa d'autorités laïques et ecclésiastiques $\left(\mathrm{n}^{\circ} 1,2,6\right)$ associées à des témoins $\left(n^{\circ} 4 \mathrm{a}\right)$; ou bien sur l'annonce de témoins seuls qui s'impose progressivement $\left(n^{\circ} 4 b, 5\right)$. Avec l'abbé Bernard, la pratique de classer les témoins selon les parties s'impose $\left(\mathrm{n}^{\circ} 4 \mathrm{a}, 6\right)$, mais le niveau de participation de chacun (arbitre, témoin ou observateur) est exceptionnellement rappel;

- Une seule de ces notices est très précisément datée $\left(n^{\circ} 1\right)$; les autres contiennent seulement des éléments de datation par les abbatiats, des approximations sur le temps écoulé entre deux événements ou des millésimes empruntés à d'autres documents ${ }^{89}$.

87. Acta of William I, p. 33. Les différents éléments de la notice de 1076 furent insérés dans la réécriture du premier diplôme confirmatif de Guillaume le Bâtard, daté de 1061. Ainsi le préambule est particulièrement développé: il se réfère à la nécessité de confier aux témoignages des chartes les possessions des églises, les moines jugèrent utile de porter à la connaissance de la postérité, comment le moulin de Vains entra dans leur dominium.

88. Ce vocabulaire ne paraît pas en relation avec la nature des affaires traitées: la conventio ${ }^{\circ} 1$ est une confirmation d'une vente par serment; le pactum $\mathrm{n}^{\circ} 3$ est un accord complexe partageant des revenus et des droits entre un seigneur laïc et une abbaye; le pactum $\mathrm{n}^{\circ} 5$ est une concession à ferme; le donum $\mathrm{n}^{\circ}$ 4a et la redditio $\mathrm{n}^{\circ} 6$ sont des restitutions avec accroissement en échange de contre-dons.

89. Dans la notice de Saint-Jean $\left(\mathrm{n}^{\circ} 3\right)$, chaque étape est soigneusement datée, soit par un événement (la fin de la captivité de Thomas à Gorron), soit par un abbatiat (au temps des abbés Roger puis 
Le formulaire est repris des brèves notices initiales qui servirent de base aux amplifications ultérieures $\left(n^{\circ} 1,2,4 a, 5\right)$. L'usage de formules se fixe sur la notification et les signes de corroboration: dépôt sur l'autel de saint Michel $\left(n^{\circ} 4,6\right)$, serments $\left(\mathrm{n}^{\circ} 3,4\right)$ en présence de reliques ( $\mathrm{n}^{\circ} 6$, le bras de saint Aubert), témoins ou/et interventions ducales $\left(n^{\circ} 1,2,3\right)$. L'évolution des moyens d'authentification et de validation internes des actes modifia sensiblement leurs modes de création et d'archivage. La validité des notices ne reposait pas sur l'usage rigoureux d'un formulaire, mais sur la structure narrative et la crédibilité de l'enchaînement des faits qu'elles remémoraient ${ }^{90}$. Leur simplicité maintenait cependant une certaine diversité des formules et n'était pas une innovation ${ }^{91}$.

Telle qu'elle se présente à nous, la documentation montoise est le résultat de nombreuses réécritures, jusqu'à la rédaction du cartulaire lui-même. Dans celui-ci, les actes normands les plus anciens, remontant au règne de Richard II, sont des diplômes ducaux ${ }^{92}$ ou des chartes de membres de la famille ducale, corroborées par le duc ${ }^{93}$. Ils présentent un discours diplomatique très développé notamment dans les préambules. Les premières chartes privées conservées pour la Normandie ne sont pas antérieures au règne de Robert le Magnifique. Elles peuvent être d'une grande simplicité formelle ${ }^{94}$, ou au contraire adopter un formulaire développé ${ }^{95}$. Les diplômes ducaux connurent une simplification diplomatique après le règne de Richard $\mathrm{II}^{96}$. Malgré les apparences, les actes privés évoluèrent assez peu durant le $\mathrm{XI}^{\mathrm{e}}$ siècle, car le cartulaire a conservé des chartes brèves pour la Touraine et le Maine depuis la fin du $\mathrm{X}^{\mathrm{e}}$ siècle ${ }^{97}$. Pour le premier

Richard), soit par un millésime. Jacques Boussard a démontré que ce dernier - 1121, indiction XI, concurrent VI - était fautif: en 1121, l'indiction était XIV et le concurrent V. Ceux du texte correspondraient à l'année 1133 qui de toute façon ne peut être retenue puisque l'abbé Richard mourut en 1131. L'éditeur a donc préféré retenir 1106/1131 (Boussard, «Thomas de Saint-Jean le Thomas et l'abbaye du Mont Saint-Michel», p. 91); ces éléments de datation pourraient appartenir à des états distincts de rédaction (voir infra).

90. Analysant les notices de la Trinité de Vendôme, Dominique Barthélemy remarque que ces écrits «sont loin d'avoir la «liberté» d'une chronique; ils sont au contraire étroitement liés aux exigences de l'argumentation judiciaire» (BARThÉLEmy, La société dans le comté de Vendôme..., p. 32)

91. RADN, p. 47-48, à propos de l'influence des notices de Marmoutier sur la simplification de la diplomatique normande.

92. Cartulary of Mont Saint-Michel, $\mathrm{n}^{\circ} 52$ ou RADN, $\mathrm{n}^{\circ}$ 12, p. 85-86, 1009; Cartulary of Mont SaintMichel, $\mathrm{n}^{\circ} 3$ ou RADN, $\mathrm{n}^{\circ} 47$, p. 155-156, 1017/1026; Cartulary of Mont Saint-Michel, $\mathrm{n}^{\circ} 2$ ou RADN, $\mathrm{n}^{\circ} 49$, p. $158-162,1025 / 1026$.

93. Cartulary of Mont Saint-Michel, $\mathrm{n}^{\circ} 31$ et 60 ou RADN, $\mathrm{n}^{\circ}$ 16, p. 96-98, vers 1015; Cartulary of Mont Saint-Michel, $\mathrm{n}^{\circ} 4$ ou RADN, $\mathrm{n}^{\circ}$ 17, p. 98-100, 1015.

94. Cartulary of Mont Saint-Michel, $\mathrm{n}^{\circ} 33,1026 / 1035$ : Ego Restaldus nauclerus quondam Roberti normannie comitis...

95. Ibidem, $\mathrm{n}^{\circ} 13$, aucun élément de datation: trois frères Rainaldus, Guillaume et Geoffroi complètent l'aumône de leurs parents à Fulquerevilla (Saint-Germain-sur-Ay, Manche, cant. Lessay).

96. RADN, p. 51-52; ibidem, $\mathrm{n}^{\circ} 65$, p. 195-197, 1032/1033 est le premier exemple d'un diplôme au protocole simplifié. En revanche les formules finales demeurèrent longtemps plus développées.

97. Cartulary of Mont Saint-Michel, $\mathrm{n}^{\circ}$ 31, 21 mars 966 ou KeATs-RoHAN, "Une charte de l'abbé Mayeul de Cluny...», p. 166-167; Cartulary of Mont Saint-Michel, $\mathrm{n}^{\circ}$ 27, 28 ou Cartulaire du prieuré de Saint-Victeur au Mans, éd. Arthur BERTRAND DE Broussillon, Paris, 1895, n I, p. 1-2, aumône de Raoul vicomte du Maine vers 994; Cartulary of Mont Saint-Michel, nº 35, 1014 ou ibidem, 
quart du XI ${ }^{e}$ siècle, l'absence de ce type de chartes privées dans le fonds normand de l'abbaye s'explique par le diplôme de confirmation générale de la fin $\mathrm{du}$ règne de Richard II qui, probablement, les fit disparaître vers 1025/1026 ${ }^{98}$. La simplicité du formulaire des notices narratives s'inscrit donc dans la continuité de la production du scriptorium de l'abbaye depuis la fin du $\mathrm{X}^{\mathrm{e}}$ siècle. Le passage à la notice narrative fut préparé par les habitudes des scribes de l'abbaye qui motivaient les aumônes privées par des notations circonstanciées dès la décennie $1040^{99}$ et copiaient sur une même pièce de parchemin, les dons initiaux ainsi que les confirmations ou les modifications ultérieures ${ }^{100}$.

La notice de Saint-Jean $\left(\mathrm{n}^{\circ} 3\right)$ permet d'étudier la manière dont les moines rendirent compte par écrit des échanges oraux dans le règlement d'une affaire. Le texte prétend relater quatre épisodes distincts, dont deux conventions orales et deux confirmations, l'une royale à Arganchy et l'autre de Thomas et des siens à l'abbaye. Le premier engagement oral concernait le partage des droits et des services des vassaux de Thomas et de l'abbaye. Le second contenait l'hommage de Thomas et un accord sur l'usufruit des bois. Comme l'a montré Jacques Boussard, les éléments chronologiques fournis par la notice sont incohérents ${ }^{101}$. Il reste toutefois la possibilité que le paragraphe décrivant les corroborations de la notice dans son état actuel ait été «bricolé» à partir d'un texte initial progressivement amplifié jusqu'à la rédaction du cartulaire. Les deux conventions orales furent réunies dans un testamentum dressé dans le chapitre du Mont SaintMichel au temps de l'abbé Roger II (1106-16 octobre 1123). Parmi les témoins de celui-ci figurait l'évêque d'Avranches Turgis (1096-16 janvier 1133), signalé dans l'entourage de Thomas lors du second accord. Cette étape correspondrait au millésime de 1121 situé à la fin de la notice finale. Mais une souscription au moins est antérieure à cette date, celle d'Othoël de Subligny. Ce personnage est assez bien connu, puisqu'il s'agit d'un membre de la famille vicomtale d'Avranches, les Goz. Il était le fils illégitime d'Hugues le Loup, vicomte d'Avranches et comte de Chester ${ }^{102}$. Mais il mourut le 25 novembre 1120 dans le naufrage de la Blanche $\mathrm{Nef}^{103}$. Dans la liste des souscripteurs, son nom est associé à celui d'un

$\mathrm{n}^{\circ} \mathrm{IV}, \mathrm{p} .5-6$. En outre, une formule de notification (notum volo esse omnibus tam presentibus quam futuris quod...) figure dans les plus anciennes chartes relatives au Maine (Cartulary of Mont Saint-Michel, $\mathrm{n}^{\circ} 26$ et Ibidem, $\mathrm{n}^{\circ} 47$ ou Cartulaire de l'Abbayette (997-1427), éd. Arthur BerTrand De Broussillon, Bulletin de la commission historique de la Mayenne, t. 9, Paris, 1894, $\mathrm{n}^{\circ} 1$ et 2, p. 9-13, 12 octobre 997$)$.

98. RADN, $\mathrm{n}^{\circ} 49$, p. 158-162; situation comparable à Jumièges, voir BATES, «La mutation documentaire...», p. 44.

99. Cartulary of Mont Saint-Michel, $\mathrm{n}^{\circ} 8$ ou RADN, $\mathrm{n}^{\circ}$ 110, p. 270-271, 1037/1042: Adelelmus miles transmit à l'abbaye le bénéfice reçu de Robert le Magnifique; puis l'acte fut corroboré par Guillaume le Bâtard.

100. RADN, $\mathrm{n}^{\circ} 73-111$, p. 210-214 et p. 272; Cartulary of Mont Saint-Michel, $\mathrm{n}^{\circ} 43$ ou RADN, $\mathrm{n}^{\circ}{ }^{\circ}$, p. 305-307, 1054/1055.

101. Boussard, «Thomas de Saint-Jean-le-Thomas et l'abbaye du Mont Saint-Michel... », p. 91-93.

102. Warren Hollister, Henry I, p. 342.

103. OV, XII-26, t. VI, p. 296-304: Othuerus etiam frater ejus [Ricardus Cestrae comes], Hugonis Cestrae comitis filius, tutor regiae prolis et pedagogus ut fertur dum repentina fieret ratis subversio, 
Gilbert d'Avranches, qui pourrait avoir été soit son oncle ${ }^{104}$, soit son petit-fils ${ }^{105}$. L'association avec Othoël et l'absence du fils de celui-ci, Hasculf de Subligny (gendre de Gilbert), invite à identifier Gilbert au plus vieux des deux, Gilbert II Goz. Un troisième souscripteur, Robert d'Avranches (qui n'est pas un Goz), appartenait à la même génération ${ }^{106}$. Ces trois personnages, dont les souscriptions sont placées immédiatement après celles de Thomas et de ses frères, souscrivirent probablement un premier document vers 1106/1120. Cette hypothèse conduit à rapprocher les deux extraits du texte consacrés à l'usage des bois de Bevais. Il est en effet étrange que le récit sépare l'accusation d'usurpation de la reconnaissance des droits de Thomas par l'abbé qui en profite pour exprimer sa défiance à l'égard de la sincérité des laïcs ${ }^{107}$. Ce premier règlement pourrait être en relation directe avec la victoire de Tinchebray en 1106. L'affaire relatée par la notice prendrait alors l'épaisseur chronologique d'une vingtaine d'années.

Le testamentum de 1121 fut porté, quelques années plus tard, à la confirmation d'Henri I ${ }^{\text {er }}$ à Arganchy ${ }^{108}$ par l'abbé Richard (1123/1124-1128). Puis Thomas, de retour au Mont Saint-Michel avec ses frères, aurait réitéré sa corroboration. Ces étapes furent antérieures à 1128 et postérieures à la fin de la captivité de Thomas

nobiliumque irreparabilis dimersio, adolescentulum ilico amplexatus est et cum ipso in profundum irremeabiliter prolapsus est.

104. Parmi les bienfaiteurs de l'abbaye de Saint-Sever vers 1066/1070 figure un Gilbert Goz frère du vicomte d'Avranches Hugues le Loup (Musset, Lucien, «Les origines et le patrimoine de l'abbaye de Saint-Sever", in La Normandie bénédictine au temps de Guillaume le Conquérant, Lille, Facultés catholiques, 1967, p. 362 et p. 365, n. 46; Musset, Lucien, Les actes de Guillaume le Conquérant et de la reine Mathilde pour les abbayes caennaises, Caen, $M S A N, 1967, \mathrm{n}^{\circ} 25$, p. 134135, 1079-1101). Il apparaît dans un acte du prieuré de Sacey (Manche, cant. Pontorson) vers 1096/1120 (BnF, ms. lat. 5441, t. II, n ${ }^{\circ} 76$, p. 161); la fille de ce Gilbert, Denise, épousa Hasculf, fils d'Othoël (Dubosc, François-Nicolas, Cartulaire de la Manche. Abbaye de la Luzerne, SaintLô, 1878, $\mathrm{n}^{\circ}$ 1, p. 1; PIgeon, Émile-Auber, Le dicocèse d'Avranches, nº 1, p. 669-671; Gallia Christiana, t. XI, Instrumenta, Ecclesiae Constantiensis, $\mathrm{n}^{\circ} \mathrm{XII}$, col. 112-113).

105. Power, Daniel, The Norman frontier in the twelfth and early thirteenth centuries, Cambridge, 2004, p. 518. Ce Gilbert II d'Avranches serait le petit-fils du précédent et le fils d'Hasculf de Subligny.

106. Il était le fils de Guillaume fils de Guimond attesté en 1066 (Cartulary of Mont Saint-Michel, $\mathrm{n}^{\circ}$ 73) et d'une fille de Baudouin de Meules; Guillaume fils de Guimond mourut la même année que Guillaume le Conquérant (OV, VIII-1, t. IV, p. 112-113, n. 9); Robert d'Avranches apparaît dans les actes du Mont Saint-Michel et de Savigny jusqu'en 1129 (Cartulary of Mont Saint-Michel, $\mathrm{n}^{\circ} 71,1104$; Cartulary of Mont Saint-Michel, $\mathrm{n}^{\circ} 72,1129$; Van Moolenbroek, Vital l'ermite..., $\mathrm{n}^{\circ}$ 2, p. 260, 25 janvier 1113).

107. Cartulary of Mont Saint-Michel, $\mathrm{n}^{\circ}$ 16, p. 96: «Quoniam ut ait Dominus, filii hujus seculi prudentiores filiis lucis sunt (Saint-Luc, XVI, 8), si non crederemus nos vestris fallacibus et fraudulentis verbis decipi, vos in primis consortes et cumparticipes beneficiorum hujus ecclesie efficeremus, et deinde $\mathrm{XX}^{\text {ti }}$ solidos, ut petitis alternaremus, et in morte et in vita vobis benigno amore hec omnia concederemus."

108. La présence du sénéchal Robert de la Haye (la Haye-du-Puits, Manche, ch.-l. cant.), qui avait obtenu d'Henri Ir l'honneur d'Eudes Haldup fondateur de l'abbaye de Lessay, s'explique par le mariage de sa fille Cécilia avec Roger de Saint-Jean (Stapleton, Thomas, Magni Rotuli Scaccarii Normanniae sub Regibus Angliae, Londres, 1840-1844, t. I, p. xcviii). 
à Gorron, soit en $1118^{109}$, soit après $1123^{110}$. Enfin d'autres témoins (Raoul de Vehun/Vains ou Raoul de Brei) sont plutôt caractéristiques de l'abbatiat de Bernard ( 5 février $1131-8$ mai 1149$)^{111}$, et s'accorderaient avec le millésime de 1133 fourni par l'indiction et le concurrent. Ainsi, le scribe regroupa à la fin de la notice les souscriptions et les éléments de datation correspondant à quatre états de rédaction: un premier groupe de témoins attesta une première convention sur l'usufruit des bois de Bevais vers 1106/1118, complétée par un second accord sur les services de chevaliers aux environs de 1118/1121 (Thomas et ses frères auraient alors réitéré leur corroboration), puis une confirmation royale sous l'abbatiat de Richard (1123/1128) ${ }^{112}$ et enfin une ultime série de témoins en 1133 . La réalisation de ce patchwork fut au plus tard contemporaine de la mise en chantier

109. Gorron, Mayenne, ch.-1. cant.; en 1118, Thomas et ses frères, Roger et Jean, à la tête de 140 chevaliers furent défaits par les Angevins à la Motte-Gautier-de-Clinchamps, puis se rendirent auprès du roi à Argentan (OV, XII-4, t. VI, p. 194-196); il est possible que ce revers ait été suivi d'une brève période de captivité. La notice de Saint-Jean présente une grande similitude avec un autre diplôme de 1118 (Regesta Henrici Primi, $\mathrm{n}^{\circ}{ }_{1183}$ ): Richard évêque de Bayeux, Jean évêque de Lisieux, Guillaume d'Aubigny, Robert de la Haye et Guillaume de Tancarville attestèrent en présence de Thomas de Saint-Jean un acte d'Henri I ${ }^{\text {er }}$ daté lui-aussi d'Argenteium (VAN MooLENBROEK, Vital l'ermite..., p. 257 et charte ${ }^{\circ}$ 6, p. 266-267).

110. Thomas de Saint-Jean revint en Normandie avec le roi en 1123 (Regesta Henrici Primi, ${ }^{\circ}{ }^{1400-}$ 1401-1418); à cette date les circonstances dans lesquelles Thomas aurait pu connaitre une période de captivité ne sont pas connues. Richard évêque de Bayeux, Jean évêque de Lisieux, Guillaume d'Aubigny et le sénéchal Robert de la Haye attestèrent aussi un acte d'Henri I Ir pour Saint-Étienne de Caen, daté de 1120/1126, à propos du prieuré Saint-Léonard de Vains (Arch. dép. Calvados, H 3673).

111. Raoul de Vains et Raoul de Brei (Cartulary of Mont Saint-Michel, $\mathrm{n}^{\circ} 77$; Cartulary of Mont SaintMichel, $\mathrm{n}^{\circ}$ 93; Cartulary of Mont Saint-Michel, $\mathrm{n}^{\circ}$ 98; PIGEON, Le diocèse d'Avranches, Coutances, 1888, n II, p. 671-672). Hugues de Hulmo (Saint-Quentin-sur-le-Homme) mourut en 1155 (Cartulaire du Mont Saint-Michel, Bibl. mun. Avranches, ms. 210, $\mathrm{f}^{\circ}$ 113, éd. Robert Genestal, Le rôle des monastères comme établissements de crédit (XI'-XIII ${ }^{e}$ s.), Paris, 1901, $\mathrm{n}^{\circ}$ VIII, p. 221). Gautier filius Hingandi (ou Hingan) attesta une charte d'Hugues d'Orval (Manche, cant. Montmartinsur-Mer), fils de Renaud d'Orval, en faveur du prieuré Sainte-Hélène dépendant depuis 1115 de l'abbaye de Lessay (Gallia Christiana, t. XI, Instrumenta, Ecclesiae Constantiensis, ${ }^{\circ} \mathrm{X}$, col. 235-236); Muriel fille de Roger de Saint-Jean épousa vers 1130 Guillaume d'Orval fils d'Hugues (STAPLETON, Magni Rotuli..., t. I, p. cxli). Philippe et Alain de Saint-Pierre [-Langers] (Manche, cant. Sartilly) apparaissent vers 1140/1144 dans l'entourage d'Hasculf de Subligny et de son frère Richard, évêque d'Avranches (1142-1154) lors de la fondation de l'abbaye de la Lucerne (Dubosc, Abbaye de la Luzerne..., 1878, $\mathrm{n}^{\circ}$ II-III, p. 1-2; Pigeon, Le diocèse d'Avranches, $\mathrm{n}^{\circ}$ 1, p. 669-671).

112. Cette hypothèse permet de restituer la cohérence du texte, car la confirmation royale entraîne une répétition plutôt maladroite: Hoc testamentum factum est in capitulo Sancti Michaelis, tempore Rogerii abbatis, et posteaquam Thomas de captione rediit de Gorron [attestation royale sous l'abbatiat de Richard]. Post hec autem reversus est Thomas cum fratribus suis ad Montem Sancti Michaelis et hoc quidem in capitulum ejusdem ecclesie reiterando corroboravit et confirmavit [...]. Thomas et ses frères corroborèrent dans le chapitre les deux premières conventions avant la présentation au roi qui s'intercale entre la mention de la libération de Thomas et sa corroboration. En elle-même, cette procédure de présentation à la confirmation royale d'un acte privé rédigé à l'abbaye était habituelle jusqu'en 1131/1133 (CHAnteux, Recueil des actes..., p. 85-90), ensuite tous les actes royaux furent expédiés directement de la chancellerie. La formule d'attestation redondante (ante piissimum et gloriosissimum regem Henricum et istis coram rege presentibus) se contentant d'indiquer la présence royale mais sans annoncer les signes de validation ou de souscription paraît elle-aussi mal raccordée au reste de l'acte. 
du cartulaire. Il n'est pas impossible que des dossiers aient existé conservant des chartes ou des notices intermédiaires, mais la rédaction de la dernière notice puis celle du cartulaire firent disparaître ces états intermédiaires dans un souci de mise à jour ou de correction du passé ${ }^{113}$.

Même si différents écrits existaient, le scribe choisit de donner à son récit l'apparence d'un dialogue publique entre Thomas et l'abbé, dans le cadre du chapitre abbatial. Il mit en scène la résolution des contentieux. Il est intéressant de distinguer les passages du texte au style subjectif, des passages intercalés au style objectif: toutes les parties dispositives sont traitées au style subjectif direct, alors que les rappels des circonstances et du cérémonial sont objectifs. Les négociations s'engagent après la clamor liturgique et les prières des moines suivies de la colère des laïcs et de leur humiliation devant l'abbé. À la fin, les laïcs demandent que leurs hommages soient reçus par l'abbé et, debout, ils prêtent serment sur les Évangiles ${ }^{114}$. Les déclarations orales de Thomas se conforment au style d'une charte de donation privée introduite par "Concedo, Domine, ut omnia domina ecclesie in pace et cum amore dimittam [...]» et conlue par «Quod nullus heredum meorum neque fratrum meorum nullo modo illam repetat ${ }^{115}$. ». Ce texte compile huit notices, énoncées par Thomas ${ }^{116}$ : quatre pour l'honneur de Saint-Pair et quatre pour l'honneur de Genêts ${ }^{117}$. Chacune de ces notices fixe les droits spécifiques de Thomas, en répétant les formules ad tantum [...] quod, eo tenore quod, tali pacto ut, tali pacto et conditione ut ou bien quoniam verissime cognovi quod ou encore quoniam certissime scio quod de dominio sancti Michaelis existunt. Chacune fut négociée: et nunc amicis nostris inter nos colloquentibus. Ces dernières formules suggèrent que les moines et Thomas enquêtèrent auprès de témoins ou d'instruments de preuves écrits. Il existait dans le chartrier de l'abbaye de brèves notes contenant le détail des opérations foncières et

113. BAtES, «La mutation documentaire...», p. 37-38.

114. Après l'annonce faite par son frère Thomas, Rogerio fratri meo [...] pro illorum servitio vobis hominium faciat et sit hujus ecclesie homo, Roger se lève et abbati hominium fecit juravitque super sacrosancta Evangelia fidelitatem ecclesie. Ensuite, Thomas venant au Mont un autre jour, abbatemque et monachos adiens ut hominium illius benigno amore susciperent. Quod et factum est. Enfin, l'abbé admit Thomas et ses frères (consortes et cumparticipes) au bénéfice de l'église: Thomas exsurgens fratresque sui cum eo, coram episcopo et omni conventu monachorum, de manibus abbatis cum textu evangelii susceperunt beneficia monachorum et eis osculatis [...]. Jusqu'en 1180, les hommages apparaîssent toujours dans des notices de plaids soit comme l'occasion de la conclusion d'un accord soit comme l'un des termes scellant celui-ci (BnF, ms. lat. 5430A, p. 270, 1131/1135; Cartulaire du Mont Saint-Michel, Bibl. mun. Avranches, ms. 210, fo $\left.113 \mathrm{v}^{\circ}, 1155\right)$.

115. Il existe d'autres exemples de ces formules préparées et répétées par les laïcs (DeLisLE, Histoire $d u$ château..., PJ, $\left.\mathrm{n}^{\circ} 46\right)$ : «Si quelque voleur et usurpateur tentait de contester cette charte, qu'il soit traduit devant le diable et ses anges, et que vif il descende en enfer, et qu'il disparaisse dans la mort éternelle, s'il ne venait pas à résipiscence».

116. Par exemple: Similiter terram Garenberti que super villam Genicii est, vobis finetenus restituo, quoniam verissime cognovi quod Robertus Filius Haymonis, cum ad monachatum venit, illam pro anime sue salute huic ecclesie dedit.

117. Saint-Pair, Manche, cant. Granville; Genêts, Manche, cant. Sartilly. 
financières intéressant son patrimoine ${ }^{118}$. Ce type d'écrits sans apparat, constituait un arsenal de preuves et devenait ensuite les matériaux dans lesquels les moines puisaient afin de rédiger des textes longs et solennels. Toutes les combinaisons étaient alors possibles en fonction des besoins ${ }^{119}$. Les déclarations de Thomas furent déjà une «mise par oral» de transactions antérieures, dont certaines étaient probablement écrites.

Tour à tour, devant un large public (parents, amis, barons, moines et clercs) l'abbé et Thomas donnèrent à voir et à entendre leurs désaccords puis leurs réconciliations. Ils puisent dans un registre complet de gestes et de paroles pour exprimer une colère (clamor liturgique; venue au Mont avec parents, compagnons et intercesseurs), un repentir (prosternation aux pieds de l'abbé; confession des fautes; requêtes pieuses; offre de négociation), un pardon conditionnel et réticent (ouverture de pourparlers; dénonciation de la perfidie des laïcs) et enfin le rétablissement de la concorde (les laïcs reçoivent le beneficium entre les mains de l'abbé; hommage; baiser). Malgré l'impression de spontanéité, il n'y eut aucune improvisation. Ces scènes ritualisées, qui se répètent de notice en notice, puisaient dans un répertoire institutionnalisé de gestes et de paroles, intégré par les acteurs eux-mêmes. Elles permirent de satisfaire aussi bien l'honneur de l'abbé, que celui de Thomas et de ses frères ${ }^{120}$ : les menaces furent mesurées (pas d'excommunication), les effusions furent contrôlées (des larmes pour les moines mais pas pour Thomas) et l'humiliation de Thomas resta très limitée (une autre notice décrit une flagellation devant l'autel, $n^{\circ} 6^{121}$ ). Ce prix ne dut pas lui paraitre trop lourd, car il sortait incontestablement renforcé de cette confrontation. La valeur dispositive est ainsi totalement absorbée par les gestes et les paroles, rassemblant les différents éléments d'une (ou de plusieurs) charte(s), insérée(s) dans la notice.

La ligne de partage entre récit circonstanciel et oralité dispositive paraît nette, mais les deux furent réunis dans le même acte. L'accumulation d'éléments narratifs était destinée à valider le dispositif ${ }^{122}$. Car un récit cohérent et crédible

118. Un parchemin provenant du chartrier du Mont Saint-Michel, conservé aux Archives départementales de la Manche jusqu'en 1944 (H 15173), contenait six brèves notices concernant les habitants de la villa de Genêts (Manche, cant. Sartilly; Arch. dép. Calvados, F 5276) : un pactum sur la cession d'un tiers d'église; quatre prêts gagés sur des parts d'une église et d'un moulin; la vente d'une maison et d'une autre part d'église. Toutes ces opérations remontaient à l'abbatiat de Renouf (1053/1055-1084/1085) et concernaient une douzaine d'hommes alternativement partie, caution (fidejussor et plegium) et témoins. Ces notices sont absolument comparables à celles qui constituent le dispositif de la notice narrative de Saint-Jean. Elles contiennent des informations précises sur les circonstances des différents transferts de biens et des droits qui s'y rattachaient.

119. Musset, Les actes de Guillaume le Conquérant..., p. 25-35.

120. Althoff, Gerd, "Les rituels", in Les tendances actuelles de l'histoire du Moyen Âge en France et en Allemagne, Schmitt, Jean-Claude, Oexle, Otto Gerhard (dir.), Paris, 2002, p. 231-242; GAUvard, Claude, «Le rituel, objet d'histoire», ibidem, p. 269-281; Gauvard, Claude, Boureau, Alain, JАСОВ, Robert, DE MirAMON, Charles, «Normes, droit, rituels et pouvoir», ibidem, p. 461-482.

121. Cartulary of Mont Saint-Michel, $\mathrm{n}^{\circ} 88$.

122. Une étude comparable d'une «notice-charte» permettant d'utiles recoupements a été publiée par Chantal Senséby, "Une notice fausse du cartulaire de l'abbaye tourangelle de Noyers?», 
des circonstances, qui avaient été marquées par une succession de crises et de pactes, contribuait à la reconnaissance de l'authenticité des dispositifs. L'accumulation narrative est un choix stylistique du scribe, entremêlant mise par écrit et oralité ${ }^{123}$. Cela renforçait la solennité des engagements de Thomas et de ses frères en jouant sur la complémentarité des modes de communication en fonction des destinataires présents et futurs. L'écriture accompagnait la progression des pourparlers et fut, autant que les gestes et les paroles, objet de discussion.

Contre Thomas de Saint-Jean, les moines s'abstinrent de produire des preuves écrites conventionnelles et solennelles à l'appui de leur réquisitoire. Pourtant, des écrits existaient. Ils se retrouvèrent, trente ans après, copiés dans le cartulaire, sous la forme d'une première confirmation de Richard II (1022/1026) ${ }^{124}$ et d'une seconde émanant du duc Robert son fils (1027/1035) ${ }^{125}$. Elles contenaient les aumônes de Saint-Pair et de Saint-Jean-sur-Mer, y compris la forêt de Bevais. Pour Genêts, une tradition faisait remonter l'aumône à saint Aubert lui-même ${ }^{126}$. Mais ces diplômes auraient été excessifs et inadaptés. Car Thomas, comme il le «dit» lui-même, quoniam certissime scio quod de dominio sancti Michaelis existunt, ne contestait pas la propriété des moines, mais la répartition des droits et des services avec son seigneur. De portée beaucoup trop générale, les diplômes étaient inappropriés aux relations de proximité à l'intérieur même d'une seigneurie ou d'un village. Quelle aurait été, en effet, l'efficacité d'écrits qui, bien que rigoureusement normalisés, évoquaient en termes généraux l'aumône d'une «villa»? Le règlement d'une affaire de ce genre nécessitait un dispositif pointilliste (identités et statuts des individus, la dénomination voire la portion des biens, la quantité et la valeur des revenus et des redevances). La plupart de ces informations faisaient défaut dans les actes solennels du XIe siècle. Dans ce type d'affaire, les écrits idoines étaient plutôt les notes informelles enregistrant les «micro-transactions» entre les moines et leurs vavasseurs. Bien que la noticecharte soit muette à ce sujet, on ne peut conclure que les moines négligeaient les preuves écrites dans la défense de leurs intérêts.

La question de la valeur des diplômes ducaux dans le règlement des conflits est posée dans la notice relative au moulin de Vains. L'écrit y occupe, au contraire de l'exemple précédent, une grande place dans l'argumentation des moines.

in Pratiques de l'écrit documentaire au XI siècle..., p. 61-94, notamment p. 76, à propos de la combinaison de la narration objective et du style direct, c'est-à-dire de discours à la première personne ayant valeur dispositive. À propos de l'hybridation des styles selon les nécessités entre "écrits d'accomplissement» et "écrits mémoriaux", voir aussi Dominique BARThÉlemy, «Une crise de l'écrit?... », p. 99-101.

123. Guyotjeannin, Olivier, "Penuria scriptorum: le mythe de l'anarchie documentaire dans la France du nord ( $\mathrm{X}^{\mathrm{e}}$ - première moitié du $\mathrm{XI}^{\mathrm{e}}$ siècle)», in Pratiques de l'écrit documentaire au $X I^{e}$ siècle..., p. 13-14; Keller, Hagen, "Oralité et écriture», in Les tendances actuelles de l'histoire..., 127-142.

124. $R A D N, \mathrm{n}^{\circ} 49$, p. $158-162$.

125. $R A D N, \mathrm{n}^{\circ} 73$, p. 210- 214; nous disposons de deux versions sensiblement différente de ce diplôme: un fac-similé de l'original (Arch. dép. Calvados, F 5690) et sa copie rallongée par l'interpolation d'une charte de Guillaume le Bâtard dans le cartulaire (Cartulary of Mont Saint-Michel, $\mathrm{n}^{\circ}{ }_{5}$ ).

126. Cartulary of Mont Saint-Michel, p. 67, Revelatio ecclesie sancti Michaelis. 
Le préambule rappelle que: Antiquorum sollers providentia approbabili more instituit super quasque possessiones aecclesiarum cartarum adhiberi testimonia quibus viriliter opprimatur quotiens emerserit calumpniatorum pervicax insolentia. Ea ergo intentione, commodum duximus noticie posterorum tradere $[. . .]^{127}$. Puis les moines citent successivement un cyrographum du duc Robert, cum terribili anathemate, et corroboré par sa main, puis un scriptum du prince Guillaume, confirmant ce don en présence de ses fidèles ${ }^{128}$, et enfin une membranula copiée dans la notice même, par laquelle le même prince reconnaît avoir reçu trente livres pour sa confirmation ${ }^{129}$. Or, malgré cet arsenal de preuves fourbies par les moines, un certain Jean fils de Richard contesta la propriété des moines, «ignorant le preceptum royal et n'accordant pas foi à ces justes preuves ${ }^{130}$ ». Comment interpréter l'obstination de Jean face à de telles preuves? Nous ignorons l'objet de la calumnia de Jean. Mais la possession garantie par les diplômes était-elle de nature à l'écarter des droits qu'il prétendait détenir sur le moulin? Le dossier rassemblé par les moines était-il aussi solide qu'ils le prétendaient? La propriété transférée par le duc était-elle en contradiction avec les droits de tiers? Le refus de reconnaître la validité du précepte ducal entraîna la saisine de la cour ducale. Les juges ducaux, puis le duc lui-même, confirmèrent la propriété de l'abbaye sur le moulin. L'exhibition des trois actes ducaux par les moines était surtout destinée à obtenir une réitération de la confirmation ducale. Reste à savoir si cela suffit à trancher la querelle. Rien ne prouve en effet que l'abbé ne dut pas, comme quinze ans plus tôt contre Waleran fils du monétaire Renouf, reconnaître ou racheter les droits de Jean fils de Richard. La valeur probatoire de l'écrit était donc un enjeu entre les parties aussi bien sur la forme que sur le fond ${ }^{131}$.

Cinquante ans plus tard, en 1134, un procès entre la cathédrale de Coutances et la collégiale de Cherbourg, à propos de la possession de l'église d'Aurigny, mit en débat la valeur probatoire de deux cartae de Guillaume le Bâtard ${ }^{132}$. Le jugement

127. Vers 1066/1067, certains préambules affirmaient leur confiance dans l'acte écrit. Ainsi, la pancarte de la cathédrale Saint-André d'Avranches ( $\left.R A D N, \mathrm{n}^{\circ} 21, \mathrm{p} .24, \mathrm{n} .24\right)$ dénonce non seulement la perte des chartes anciennes mais justifie la nécessité d'établir un acte écrit incontestable. Contemporaine de celle-ci, une convention entre l'abbé Renouf et un certain Renouf vers 1071/1085 à propos de la dîme du vicus de Champeaux se contente d'un prologue dont le laconisme illustre le caractère banal: l'abbé du Mont Saint-Michel Renouf a fait mettre par écrit cette convenientia (Cartulary of Mont Saint-Michel, $\mathrm{n}^{\circ}$ 74).

128. $R A D N, \mathrm{n}^{\circ} 148$, copie A2

129. $R A D N, \mathrm{n}^{\circ} 148$, copie $\mathrm{A} 1$, la liste des témoins ayant été complétée par celle de $\mathrm{A} 2$.

130. Acta of William I, $\mathrm{n}^{\circ} 214$, p. 673-674: [...] Johannes ad calumnpniandum idem molendinum insperate prosiliit [...] et quasi precepto ejusdem incliti regis ipso penitus ignorante, saisivit illud, non premissa juste probationis audientia.

131. BarthéLemy, La société dans le comté de Vendôme..., p. 668.

132. Fontanel, Julie, Le cartulaire du chapitre cathédral de Coutances, Saint-Lô, Archives départementales (collection Sources inédites sur l'histoire du département de la Manche), 2003, $\mathrm{n}^{\circ} 289$, p. 429-430: [Unfridus] tunc temporis [ecclesiam Sancte Marie de Insula Aurenoii] injuste tenebat tanquam illam que de jure Constantiensis erat ecclesie de antiquo, sicut carta patris mei quam habeat contestabatur, unde quoque [canonici Cezariburgi] cartam, que communi consideratione curie mee et eorum qui [affuerunt] cassata et falsata fuit, in medium protulerunt. Contrairement à Henri $I^{\text {er }}$ et aux membres de sa cour, les deux éditrices de l'acte, Marie Fauroux $\left(R A D N, \mathrm{n}^{\circ} 214\right.$, 
royal se prononça exclusivement sur la validité des preuves écrites produites par les parties, et fut en faveur du document de la cathédrale, reconnaissant celui de la collégiale comme un faux ${ }^{133}$. La décision de la justice royale ne priva pas immédiatement les chanoines cherbourgeois de cette prébende. Le titulaire la conserva à titre viager ${ }^{134}$, tandis que le roi lui-même augmentait celle-ci par divers revenus sur des biens situés dans les environs de Cherbourg ${ }^{135}$.

L'appréciation d'Henri ${ }^{\mathrm{er}}$ ne reposa pas sur le seul examen formel des actes. D'ailleurs, de ce point de vue, ceux-ci présentent des caractéristiques semblables. Ils résultent de réécritures en profondeur ${ }^{136}$. Mais, le noyau de celui de Cherbourg est malgré tout un diplôme de Guillaume le Bâtard annonçant un scellement ducal et arborant une liste de témoins crédibles. En revanche, son concurrent est constitué d'un «bric-à-brac» d'inventaires des prébendes du chapitre et des chanoines de Saint-Lô de Rouen, suivis de notices d'aumônes ducales ou privées ${ }^{137}$, enchâssé dans un apparat diplomatique stéréotypé, mais dépourvue de tout moyen d'authentification. Lors du procès, personne sans doute n'ignorait que les deux textes avaient été remaniés ou créés pour l'occasion. D'autres considérations pesèrent dans la balance.

Dans le mouvement de réforme des collégiales, commencé depuis presque un siècle, les chanoines de Cherbourg apparaissaient comme une survivance archaïque. Le mouvement réformateur se manifesta d'ailleurs à Cherbourg peu après: Mathilde l'Emperesse, fille d'Henri I ${ }^{\text {er }}$, y fonda vers 1140/1145 NotreDame-du-Vœu, une abbaye de chanoines augustiniens rapidement réformée par Saint-Victor de Paris ${ }^{138}$. L'aura de l'évêque réformateur Algare, qui s'était préalablement attaqué aux chanoines de Saint-Lô de Rouen et de Saint-Lô-surVire, avec le soutien du pape Innocent II et de l'archevêque Hugues d'Amiens, fut sans doute décisive dans le jugement final, manifestant la piètre opinion que les réformateurs nourrissaient à l'égard de la seconde génération des collèges

p. 426-432) et Julie Fontanel, n'émirent aucune réserve quant à l'authenticité de cet extrait de la notice narrative finale.

133. Les deux cartae en litige sont bien connues: FonTANEL, Le cartulaire du chapitre cathédral de Coutances..., $\mathrm{n}^{\circ} 339$, p. 483-489 et $\mathrm{n}^{\circ} 340$, p. 489-495.

134. Il mourut vers $1164 / 1173$, date à laquelle l'église d'Aurigny fut transférée par l'évêque à la communauté du chapitre (FonTANEL, Le cartulaire du chapitre cathédral de Coutances..., $\mathrm{n}^{\circ} 290$, p. 431).

135. Ibidem, $\mathrm{n}^{\circ} 339$, p. 486.

136. Les informations contenues dans les deux textes couvrent une période s'étendant de la seconde moitié du XI ${ }^{\mathrm{e}}$ siècle au premier tiers du XII ${ }^{\mathrm{e}}$ siècle. Au XIII ${ }^{\mathrm{e}}$ siècle, ils étaient conservés dans le cartulaire du chapitre cathédral de Coutances car en 1209, la collégiale Sainte-Marie de Cherbourg avait été donnée par le roi Philippe Auguste à l'évêque Hugues de Morville (FonTANEL, Le cartulaire du chapitre cathédral de Coutances..., n² 299, p. 439, octobre 1209: Philippe Auguste donne à l'évêque de Coutances, Hugues de Morville, toutes les prébendes de la chapelle castrale de Cherbourg en compensation des pertes que l'église cathédrale avait subies en Angleterre).

137. Parmi ces bienfaiteurs figure un Ricardus filius firmarii qui ne peut être antérieur au XII ${ }^{\mathrm{e}}$ siècle (Fontanel, Le cartulaire du chapitre cathédral de Coutances..., $\mathrm{n}^{\circ} 340, \mathrm{p} .492$ ).

138. Arnoux, Mathieu, Des clercs au service de la réforme, études et documents sur les chanoines réguliers de la province de Rouen, Turnhout, Brepols, 2000, p. 21 et p. 142-143. 
de clercs séculiers ${ }^{139}$. La validation du document de Coutances ne fut pas une décision technique fondée sur des arguments diplomatiques objectifs. Le jugement de la cour royale fut avant tout politique. L'efficacité probatoire d'un écrit dépendait donc fortement de celui qui le portait.

Les habitatores de la villa de Carteret $\left(\mathrm{n}^{\circ} 4 \mathrm{~b}\right)$ étaient trop humbles pour bénéficier de la considération des moines. Ils restèrent anonymes. Les liberales de la villa et les proceres de la province firent le serment de les bannir. Ce texte a d'abord été associé aux troubles politiques et sociaux consécutifs à la mort d'Henri I ${ }^{\text {er }}{ }^{40}$. Or il me semble que l'affaire fut toute autre. Dans le premier accord, prévoyant la restitution de l'aumône de l'église paroissiale SaintGermain par les héritiers du bienfaiteur, figure une clause de suppression d'une «mauvaise coutume» relative au partage des dîmes de la paroisse ${ }^{141}$. Cette notice initiale portait des souscriptions classées selon les parties: du côté des laïcs sont mentionnés l'évêque de Coutances et quelques archidiacres, quatre membres de la famille seigneuriale de Carteret (Lucie veuve de Renaud de Carteret et ses trois fils Philippe, Onfroi et Geoffroi) qui avaient contesté le don paternel mais en avaient été finalement dédommagés par l'abbaye; du côté des moines figurent le prieur de Lessay Guillaume, des chanoines et des famuli de l'abbaye. Puis, une seconde affaire éclata entre les moines et les neveux d'un prêtre qui, ayant pris l'habit, avait renoncé à ses droits sur les revenus de l'autel. Enfin, l'affaire rebondit après la mort d'Henri I ${ }^{\text {er }}$, entraînant le soulèvement des habitatores de la villa. Le premier accord avait donc lésé les habitants, c'est-à-dire les hommes libres de la paroisse, les vavasseurs de la villa responsables de la distribution de la dîme ${ }^{142}$.

La qualité exceptionnelle des souscripteurs ainsi que la manière maladroite dont la clause d'abolition de la «mauvaise coutume» fut insérée dans les clauses finales de la notice initiale montrent que la question de la dîme, et non la contestation d'une aumône seigneuriale, était au cœur de la querelle. Malgré le changement de décimateur, les habitatores souhaitaient conserver un droit de regard sur le partage de la dîme. En associant les trois affaires dans une même notice, les moines brouillèrent sciemment les pistes. Ils réduisirent l'ensemble à

139. MussET, Lucien, «Recherches sur les communautés de clercs séculiers en Normandie au XIe siècle», BSAN, t. LV, 1959-1960, p. 13-19; ARnoux, Des clercs au service de la réforme..., p. 64-69.

140. DufIEF, «La vie monastique au Mont pendant le XII e siècle... », p. 98.

141. Cartulary of Mont Saint-Michel, $\mathrm{n}^{\circ}$ 82, p. 157-158: Pro his et enim novis donis supradictis et pro mala consuetudine removenda et prorsus auferenda dedit predictus abbas Bernardus Philippo VII libras rothomagensis nove monete matrisque sue unum auri bizanteum et Gaufrido fratri suo unum accipitrem et Hunfredo quasdam ocreas. [...] Illa vero mala consuetudo de qua superius mentionem fecimus hec erat quod non poterant decime collecte bladum ponere nisi curia ipsius Philippi ubi diminuebatur.

142. Musset, Lucien, "Aperçus sur la dîme ecclésiastique en Normandie au XI ${ }^{\mathrm{e}}$ siècle», in Aspects de la société et de l'économie dans la Normandie médiévale ( $X^{e}$-XIII ${ }^{e}$ siècles), Caen [Cahiers des Annales de Normandie, $\mathrm{n}^{\circ}$ 22], 1988, p. 57-58; Arnoux, Mathieu, «Remarques sur les fonctions économiques de la communauté paroissiale (Normandie, XII ${ }^{\mathrm{e}}$-XIII ${ }^{\mathrm{e}}$ siècles) », in "Liber largitorius». Études d'histoire médiévale offertes à Pierre Toubert par ses élèves, Dominique BARTHÉLEMY, Jean-Marie MARTin (éd.), Paris, EPHE, Droz, 2003, p. 417-434. 
une banale affaire de contestation d'aumône. Or, dans un esprit très grégorien, la notice confond les divers droits s'exerçant sur l'église paroissiale: ceux du patron laïc, de la famille sacerdotale et des paroissiens. L'abbé réunit progressivement tous ses droits entre ses mains ${ }^{143}$, en les incluant à la première aumône du patron laïc et en qualifiant de «mauvaise coutume» les droits des vavasseurs. La notice, qui dénonce l'appropriation illégitime des droits ecclésiastiques par les laïcs, illustre l'ambiguïté de la preuve écrite, objet d'interprétation et de manipulation. L'aumône seigneuriale fut utilisée ici afin de légitimer la suppression du contrôle paroissial sur la dîme. Dans le contexte féodal et grégorien, la relecture de la notice par les moines, voire son interpolation, élargissait de manière abusive leurs droits sur l'église.

L'exhibition des chartes n'était pas systématique et entrait dans la tactique élaborée par le plaideur en fonction des différentes étapes du conflit. Il pouvait être profitable de produire des diplômes solennels devant la curia regis, mais ceux-ci étaient inopportuns comme instrument de régulation des relations sociales au sein de la seigneurie abbatiale. Au même titre qu'un témoin ou qu'un arbitre, l'établissement de l'écrit comme preuve était suspendu à sa reconnaissance par les parties ou par l'autorité saisie par l'une d'entre elles. Les «jugements» étudiés se bornèrent à valider les preuves présentées par l'abbé. Mais de toute façon il ne s'agissait que d'une étape dans le processus d'apaisement du conflit.

Le bilan de cette étude à partir de quelques exemples ne peut être que provisoire. Les notices narratives ont séduit les historiens par la richesse de leur information et l'intérêt de leurs récits, mais ils se contentèrent d'analyses contextuelles. Charles Homer Haskins pensait qu'elles s'étaient multipliées en raison de l'intensité des troubles affectant l'Avranchin vers $1140^{144}$. Pourtant les notices de cette époque rapportent les succès de l'abbé Bernard. Les guerres ne l'empêchèrent donc pas de défendre et de revendiquer des droits au nom de l'abbaye. $A$ contrario, leur absence ou leur rareté sous certains abbés correspondirent-elles à des périodes moins troublées ou bien à des abbatiats moins énergiques? Certains des conflits réglés par Bernard avaient des racines bien plus anciennes. La rédaction du cartulaire quelques années après sa mort ainsi que l'extension du recours à l'écrit pour des conflits de moindre importance pourraient aussi expliquer l'augmentation du nombre des notices conservées. L'approche quantitative est donc peu significative et conduit à un raisonnement circulaire.

143. Longnon, Pouillés de la province de Rouen..., p. 337 C.

144. Haskins, Norman Institutions, p. 128, n. 19. 
Selon ces notices, les conflits avaient pour motif principal la «cupidité et l'avidité» de laïcs toujours prompts à dépouiller l'Église. Pourtant un examen attentif des tensions qu'elles décrivent montre que ces conflits touchaient en profondeur les structures sociales: reconnaissance des droits des héritiers $\left(n^{\circ} 4 \mathrm{a}\right)$ ou de tiers sur l'objet de la transaction $\left(n^{\circ} 4,5\right)$; droits des familles sacerdotales et des communautés d'habitants sur les dîmes paroissiales $\left(\mathrm{n}^{\circ} 4 \mathrm{~b}\right)$; mise en place de la féodalité dans l'entourage du Mont Saint-Michel $\left(\mathrm{n}^{\circ} 3\right)$; les statuts de l'aumône et de la vente $\left(\mathrm{n}^{\circ} 2\right)$; les copatronages paroissiaux $\left(\mathrm{n}^{\circ} 6\right)$. Ces conflits n'étaient pas réglés par l'application impérieuse de règles juridiques émanant d'une autorité souveraine, s'appuyant sur un système répressif. Le rétablissement de la paix troublée par de telles affaires passait par la négociation d'un nouvel équilibre social, satisfaisant les deux parties ${ }^{145}$.

Les notices narratives et les conflits qu'elles rapportent ne sont pas particulièrement associés à des périodes de troubles politiques. Le réalisme des situations et l'incarnation des protagonistes étaient le gage d'efficacité de ces écrits. Par ces notices, la détermination des moines à défendre ce qu'ils considéraient comme leurs droits prenait une réalité «palpable». La redéfinition des relations entre l'abbaye et les laïcs fut permanente. La recherche "d'une efficacité croissante de l'écrit face à une réalité mouvante», comme l'a écrit Laurent Morelle ${ }^{146}$, ne doit pas faire oublier qu'il s'agit toujours d'argumentations juridiques à charge contre les laïcs et non de relations objectives des faits et des procédures. La normalisation n'était pas dans le formulaire, plutôt réduit, mais dans les rituels qu'elles rapportaient et qui les authentifiaient aux yeux des contemporains. Ceux-ci, associés par la parole et le geste, s'y reconnaissaient davantage que dans des formules qui, pour sauver les apparences, n'auraient plus témoigné que d'elles-mêmes.

L'impression de réalité est trompeuse car les scribes n'en oubliaient pas pour autant les intérêts de leur établissement. Au Mont Saint-Michel, ils en vinrent à gommer l'intervention ducale, faisant ressortir l'autonomie de l'abbaye en matière de justice civile. Mais derrière l'éloquence et les colères des abbés, il y avait la protection de l'autorité ducale sur l'Église ${ }^{147}$. La relation entre l'écrit et le règlement des conflits étudiée dans la partie occidentale du duché, à partir d'autres sources, aurait donné une image totalement différente. À Montebourg, les brefs royaux sont nombreux ${ }^{148}$ et le cartulaire de Saint-Sauveur-le-Vicomte n'a conservé, avant 116o, qu'un unique exemple de conflit, tranché par un jugement vicomtal ${ }^{149}$.

145. Barthélemy, «La société dans le comté de Vendôme... », p. 652-666.

146. Morelle, "Les chartes dans la gestion des conflits...», p. 280.

147. BATES, «La mutation documentaire...", p. 40-43.

148. BnF, ms. lat. 10087, $\mathrm{f}^{\circ}$ 7-8; Haskins, Norman Institutions, $\mathrm{n}^{\circ} 8$, 9, 10, 11, 12, 13, 14, 15, p. 101-102, série de brefs datés de 1108/1135.

149. Jugement de la cour seigneuriale, qui est aussi vicomtale (1104/1107), à propos de la répartition des dîmes et des champarts (BnF, ms. lat. 17137, fo 19-24; Delisle, Histoire du château..., PJ, $\mathrm{n}^{\circ} 48$, p. 60). 
La forme de réécriture des actes par notices narratives ne conquit pas les autres monastères de l'Avranchin et du Cotentin. Le scriptorium de Saint-Sauveurle-Vicomte préféra la pratique des pancartes dont cette abbaye se fit une sorte de spécialité. Quant à Montebourg, les seules compilations d'actes reproduites dans le cartulaire furent les confirmations. La spécificité des notices narratives $\mathrm{du}$ Mont s'explique sans doute par son intense production historiographique relative aux origines normandes de l'abbaye qui déboucha sur la rédaction d'un cartulaire-chronique à partir de 1150. Les notices narratives permirent la poursuite du récit historique sur l'abbaye et la défense ou l'accroissement de son patrimoine. Seuls les plus édifiantes furent conservées ${ }^{150}$, par un processus de sélection dans lequel le discours de l'abbaye sur elle-même et son passé pesa lourd. Elles furent aussi un moyen d'éclairer l'action jugée positive de certains abbés au détriment de ceux dont les moines ne souhaitèrent pas illustrer l'abbatiat et qui demeurèrent dans l'ombre. La communauté et ses abbés successifs s'y mettaient en scène, perpétuant le souvenir des actions à louer ou à dénoncer ainsi que les hommes à sauver ou à condamner ${ }^{151}$.

150. Morelle, «Les chartes dans la gestion des conflits...», p. 273, n. 29, à propos de la sélection documentaire opérée dans la chronique-cartulaire d'Hariulf consacrée à Saint-Riquier, ne retenant que les documents présentant «une valeur morale, montrant un laïc venu à résipiscence».

151. L'abbé Bernard y était qualifié de vir sapientissimus ac disertissimus et nimie eloquencie (Cartulary of Mont Saint-Michel, $\mathrm{n}^{\circ}$ 98, p. 172) tandis que le corps de Roger le camérier demeura sans sépulture (BnF, ms. lat. $\left.5430 \mathrm{~A}, \mathrm{f}^{\circ} 270\right)$ : Quo in malitia perseverante cum et asinum qui pauperibus Dei aquam deferret, cepisset illico Domini et archangeli Michaelis sagitta percussus nec diutius vivens sine absolutione excommunicationis ecclesie est defunctus et iccirco sicut nunc usque apparet super terram jacet inhumatus. 